\title{
Asymmetric Information and the Death of ABS CDOs
}

Beltran, Daniel, Larry Cordell, and Charles P. Thomas

Please cite paper as:

Beltran, Daniel, Larry Cordell, and Charles P. Thomas (2016).

Asymmetric Information and the Death of ABS CDOs.

International Finance Discussion Papers 1075r.

https://doi.org/10.17016/IFDP.2016.1075r

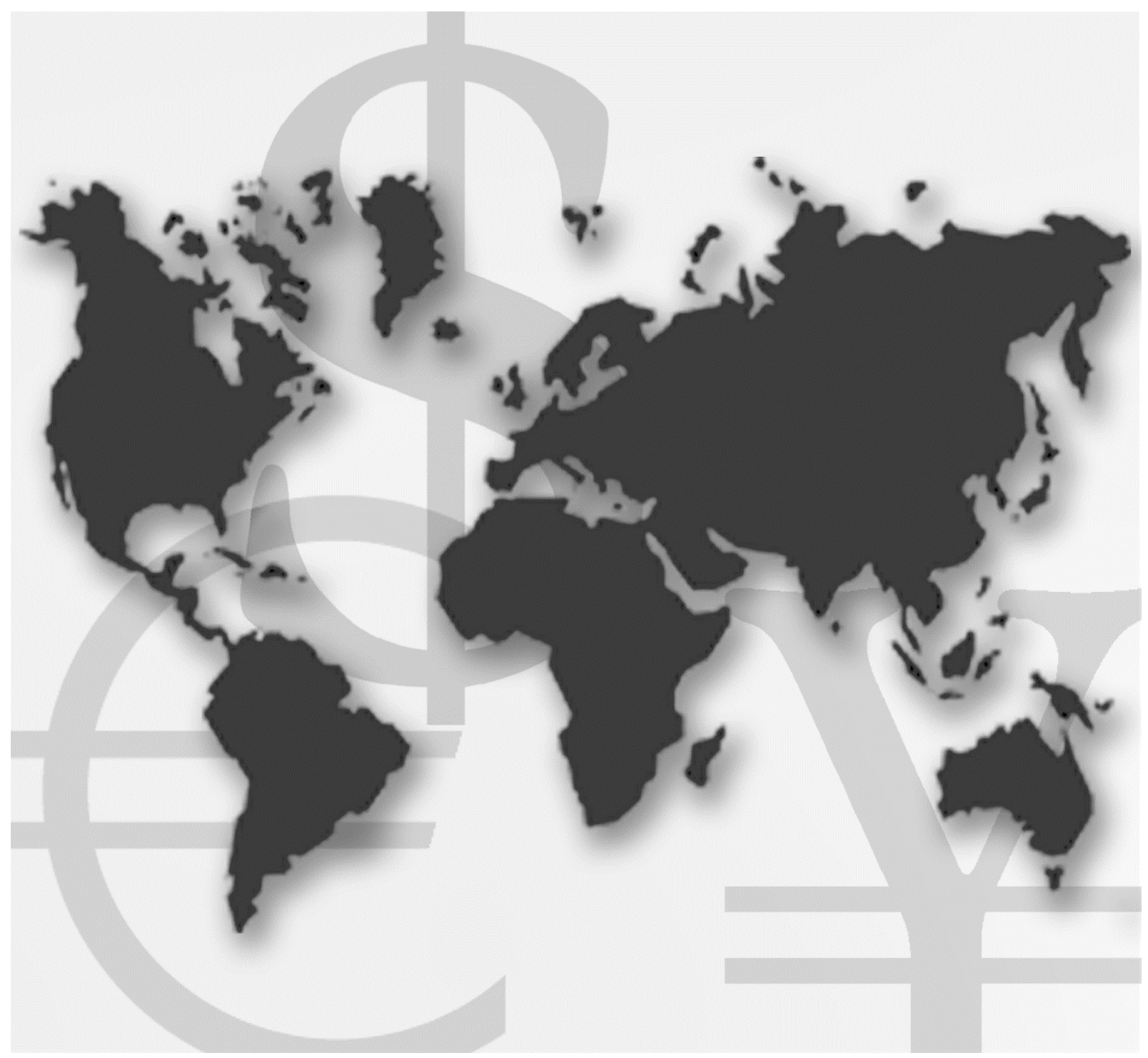

\section{International Finance Discussion Papers}

Board of Governors of the Federal Reserve System

Number $1075 r$

November 2016 


\title{
Asymmetric Information and the Death of ABS CDOs*
}

\author{
Daniel O. Beltran ${ }^{\dagger} \quad$ Larry Cordell ${ }^{\ddagger} \quad$ Charles P. Thomas ${ }^{\S}$
}

November 16, 2016

\begin{abstract}
A key feature of the 2007 financial crisis is that for many securities trading had ceased; where trading did occur, market prices were well below intrinsic values, especially for ABS CDOs. One explanation is that information had been asymmetric, with sellers having better information than buyers. We first show the information advantages sellers had over buyers in both the issuance of CDOs and, through vertical integration, performance of the CDO collateral that could well have disrupted trading after the onset of the crisis. Using a "workhorse" model for pricing securities under asymmetric information and a novel dataset, we show how adverse selection could explain why the bulk of these securities either traded at significant discounts or did not trade at all.
\end{abstract}

Keywords: CDO, securitization, asymmetric, lemons

JEL Classification: C63, D82, D43

\footnotetext{
*We thank Meredith Williams and Yilin Huang for providing us with crucial data, and Ronel Elul for discussing an earlier version of this paper at the Global Financial Crisis research workshop held at the Federal Reserve Board. We are also indebted to Gene Phillips, Gregory Feldberg, John Ammer, Neil Ericsson, Anil Jain, and participants of the 2010 International Risk Management Conference in Florence, International Atlantic Economic Society conference in Canada, and Office of Financial Research seminar for helpful comments. Michelle Welch, Grant Long, and Zachary Kurtz provided excellent research assistance. The views in this paper are solely the responsibility of the authors and should not be interpreted as reflecting the views of the Board of Governors of the Federal Reserve System or of any other person associated with the Federal Reserve System.

${ }^{\dagger}$ Federal Reserve Board of Governors, Address for correspondence: 20th and C St. NW, Mail Stop 38, Washington, DC 20551. Email: daniel.o.beltran@frb.gov. Phone: +1(202)452-2244.

${ }^{\ddagger}$ Federal Reserve Bank of Philadelphia

$\S$ Federal Reserve Board of Governors
} 


\section{Introduction}

Collateralized debt obligations (CDOs) were at the heart of the 2007-2008 financial crisis. By January 2009, global banks, insurers, and asset managers had taken $\$ 218$ billion in losses from their holdings of CDOs of asset backed securities (ABS), on top of $\$ 84$ billion of losses on residential mortgage backed securities (RMBS) largely backed by private label U.S. subprime mortgages (see Table 1). These firms were being penalized by markets for having these "toxic" assets on their balance sheets, and would have probably sold them at prices close to the fair liquidation value of the underlying collateral if they could have. But secondary market prices were well below intrinsic values, and selling in this distressed market would have crystallized losses and eroded their capital position even further. The uncertainty surrounding the size and location of these CDO-related losses contributed to heightened counterparty risk, which in turn led to the collapse of interbank funding markets, setting off the Panic of 2007 (Gorton, 2009). This collapse was likely amplified by interlinkages between ABS prices and liquidity provision through the shadow banking system (Gorton and Metrick, 2012; Caballero and Simsek, 2009) and the deleveraging cycle that took place as a result of procyclical active balance sheet management (Adrian and Shin, 2010).

The main contribution of this paper is to show that, even absent these factors, asymmetric information (AI) between buyers and sellers regarding the quality of ABS CDOs was strong enough to shutter this market. First, we connect a straight-forward extension of the Akerlof (1970) lemons model to data on the quality of CDOs, and show that the distribution of the CDOs' intrinsic values was so disperse that relatively limited AI regarding these values would have impaired trading. That is, even if all market participants had identical, perfect information about the distribution of the intrinsic values within fairly narrow sets of CDO securities, there were enough low-value securities to induce a lemons problem sufficient to close the market. As such, the market did not stand a chance. Also, in making this argument, the paper explains how the CDO securitization process gave sellers information advantages in the placement of collateral in CDOs. Specifically, we show how the 18 largest dealers derived information advantages from vertically integrating their mortgage pipelines from originations through servicing. Furthermore, we provide evidence suggesting that these vertically-integrated dealers used their informational advantage to originate CDOs that contained lower quality collateral compared to those of their peers who were not vertically integrated. In other words, it appears as though sellers were using their informational advantage to offload riskier securities as the market began to freeze.

Because the analysis proceeds in parts which are only joined together at the end, we provide the following roadmap: In the next section we summarize how subprime mortgages 
were securitized into ABS CDOs, and how this market collapsed in the second half of 2007, resulting in the sudden evaporation of liquidity and the dislodging of prices from intrinsic values. Having established the facts that we are trying to explain with AI, in Section 3 we describe the nature of the AI between sellers and potential buyers of ABS CDOs. In Sections 4 and 5, we lay out a "workhorse" model for pricing securities under AI, and describe a novel dataset for the intrinsic values of ABS CDOs ${ }^{1}$ In Section 6, we take these data directly to the model and show how AI between sellers and potential buyers could explain both the evaporation of liquidity and the dislodging of prices from intrinsic values. Section 7 takes a step back and asks how, given the earlier results, can we explain the existence of the market in the first place. One (easy) explanation is that the original CDO buyers did not know what they were getting into. Alternatively, we can examine the possibility that the original buyers knew everything we have assumed, including how AI would, conditional on a housing shock, shutter the market. In this case, we can ask what is the maximum probability of a housing shock that would still make the CDOs look like attractive investments. If this maximum probability is fairly high, we can imagine that buyers could have assigned a somewhat lower probability, in which case the existence of the market is consistent with the AI we have assumed. The last section concludes.

\section{Trading of CDOs and the Onset of the Financial Crisis}

Even before the crisis, secondary market trading activity for ABS CDOs was light. Because ABS CDOs were unregistered " $144 \mathrm{~A}$ " securities with their underlying collateral subject to change after issue date, they were more suitable as buy-and-hold investments.2 Also, most of the lower-rated CDO tranches were recycled into other CDOs, and thus not traded in secondary markets ${ }^{3}$ Trading took place on the over-the-counter market primarily among institutional investors such as investment banks, hedge funds, and asset managers (IOSCO, 2009). Even so, secondary market activity for CDOs increased notably between 2003 and 2005, as spreads for seasoned CDOs tightened relative to those of new-issue CDOs (Lucas, Goodman, and Fabozzi, 2006).

On July 10, 2007, both Moody's and S\&P downgraded hundreds of subprime RMBS that

\footnotetext{
${ }^{1}$ More details on the computation of these intrinsic values, which capture the fair liquidation value of the underlying collateral, can be found in Appendix A.

${ }^{2}$ Rule 144A of the Securities Act of 1933 allows private companies to sell unregistered securities to qualified institutional buyers through a broker dealer. Unregistered securities do not have disclosure requirements like public securities do.

${ }^{3}$ As shown in Table 5 of Cordell, Huang, and Williams (2012), two-thirds of BBB- and AA-rated CDO tranches were recycled into other CDOs and CDO-squareds.
} 
had been issued in 2005 and 2006, citing higher than anticipated rates of early payment defaults and fraud (Moody's Investor Service, 2007; Standard \& Poor's, 2007). Furthermore, S\&P revised their model assumptions, projecting losses on subprime MBS "as high as 11 to $14 \%$...far in excess of what we had originally projected and even what a lot of street research is telling us." 4 Since BBB subprime bonds covered losses between $4 \%-8 \%$ of the pools on average, losses of this size meant that all of these subprime bonds would be worthless..$^{5}$ Over the ensuing weeks S\&P discovered that most of the publicly-traded ABS CDOs contained these worthless bonds. In sum, investors suddenly became aware that there were lemons in the market for CDOs, but, with limited disclosure, figuring out which CDOs were lemons was tricky. Immediately following the downgrades, investors began to question the underlying assumptions of the copula models they and the ratings agencies used to estimate expected losses on ABS CDOs. These models relied on loss correlations among the bonds in the CDOs to estimate losses; on the downgraded BBB subprime bonds the correlation was now 1 . In short, the copula models became useless, and so did the ratings which appeared to have been grossly inflated.

With the onset of the financial crisis in August 2007, the ABS CDO market shut down. On August 9, BNP Paribas froze subscriptions and redemptions to several of its funds, and suspended computation of their net asset values because of "the complete evaporation of liquidity in certain market segments of the U.S. securitization market," which "has made it impossible to value certain assets fairly regardless of their quality or credit rating (New York Times, 2007)." A survey of industry participants and market authorities by the International Organization of Securities Commissions (IOSCO) found that "secondary market trading in SFPs [structured finance products] appears to have declined significantly since the onset of the credit crisis." (IOSCO, 2009) Where trades did occur, it appeared that market prices were well below what one might have believed to be the intrinsic value for that class of security $!^{6}$ In sum, the secondary market for ABS CDOs virtually disappeared, and where trades did occur, secondary market prices were dislodged from fundamentals.

\section{Information asymmetries in the market for CDOs}

Gorton (2009) argues that AI in the ABS CDO market stemmed from a loss of informa-

${ }^{4}$ Standard \& Poor's $(2007)$, p. 52.

${ }^{5}$ See Cordell, Huang, and Williams (2012), Table 1.

${ }^{6}$ A White Paper accompanying the March 23, 2009 press release announcing the details of the Public-Private Investment Program to purchase troubled assets, the Treasury stated that "while fundamentals have surely deteriorated over the past 18-24 months, there is evidence that current prices for some legacy assets embed substantial liquidity discounts." (U.S. Department of the Treasury, 2009) 
tion about the quality of the underlying loans that occurred as a result of the long chain of structures inherent in the subprime securitization process.7 We expand this argument by documenting the information advantage CDO sellers had in the securitization process and how vertical integration in the securitization of subprime mortgages provided the CDO dealers informational advantages over potential buyers.

Before the crisis, even though investors could have used commercially available valuation engines such as Intex to value CDOs, most took the simpler approach of using rating agency ratings or standard copula models, which did not value the underlying securities. These models were documented and well supported in academic and rating agency literatures. In addition, the gains to acquiring better information on the quality of these securities were likely perceived to be small because there was little dispersion in their intrinsic values while house prices were increasing rapidly and none of the subprime bonds had been downgraded. That is, before the crisis CDOs were "information-insensitive" as described in (Gorton and Pennacchi, 1990; Dang, Gorton, and Holmström, 2015): It was not believed to be necessary for investors to value the underlying collateral in the CDOs. This gave sellers of CDOs an information advantage, as many investors were unaware of the extent to which subprime securities had come to dominate ABS CDOs, which Cordell, Huang, and Williams (2012) (hereafter CHW) confirm happened in 2005-2007 when $80 \%$ of ABS CDOs were issued. $\left.\right|^{8}$ It was also the case that placement of securities took place after the issue date of the CDOs. CDOs had both a "ramp up" period and a "reinvestment period" during which new securities were placed into a CDO after the issue date. This ability to place new securities into a CDO after the issue date gave sellers and their collateral managers an information advantage over buyers on the quality of those subprime bonds.9

Another reason why sellers had an information advantage on the bonds is because they were much better informed about the deteriorating quality of subprime loans. This superior knowledge of the underlying risks derives mainly from the fact that the largest CDO dealers were vertically integrated across the entire mortgage chain. As shown in Table 2, most CDO dealers entered the business of originating and servicing mortgages by acquiring large subprime originators and servicers. Most were either fully integrated (doing originations, issuance of

\footnotetext{
${ }^{7}$ In theory, securitization could ameliorate the effects of AI when the seller signals his private information regarding the quality of the assets underlying a CDO to the buyer by retaining the riskier junior tranche (DeMarzo, 2005, DeMarzo and Duffie, 1999). But in practice, CDO issuers typically retained the most senior tranche.

${ }^{8}$ For example, documents by one large CDO investor, AIG, refer to the CDOs in their portfolio as "multisector." Actual CDOs from the New York Fed's Maiden Lane 3 portfolio that were part of the takeover of AIG confirm that $77 \%$ of their underlying collateral at issuance was mortgage bonds.

${ }^{9} \mathrm{As}$ pointed out, their $144 \mathrm{~A}$ unregistered status also did not require the same disclosures as registered securities.
} 
RMBS, issuance of CDOs, and, finally, servicing the mortgages) or were partially integrated by engaging in some part of the mortgage chain.

By owning an originator, CDO dealers would have information on the quality of the originations. By owning a servicer, they could see firsthand the early payment defaults (EPDs) and rise in delinquencies that started after house prices peaked in late 2005. If fully integrated CDO dealers were indeed taking advantage of their superior information to offload lemons from their origination lines into the CDOs they originated, then we would expect to see higher losses on the CDOs they originated relative to those of CDOs originated by dealers who were either partially integrated or not integrated. Indeed, as shown in Table 3, the average losses (weighted by deal size) of CDOs issued by the fully-vertically integrated dealers were larger than those of partially- and non-vertically integrated dealers 10 This evidence is consistent with the idea that vertically-integrated CDO dealers were using their superior information on the quality of the underlying collateral to offload lemons from their origination lines. Importantly, the vast majority of Mezzanine CDOs were issued by fully integrated CDO dealers, which further supports the notion that these dealers were using their informational advantage to offload the lower-rated tranches of ABS securities 11

\section{The model}

Having established that these securities are hard to value and that AI was present, we use a straightforward generalization of the Akerlof (1970) lemons model, described below, to analyze how these securities would trade under AI. The incentives for trade depend on the willingness of some agents to sell their securities at a discount relative to their intrinsic value. To assure that in a single period a given security only changes hands once, we assume that:

Assumption 1. After a security trades there is a significant delay before the intrinsic value is revealed to the buyer.

Even if we were to allow those who purchased securities to learn the intrinsic value of the securities they acquired, second round trades would only occur if those who bought securities in the first round of trading all of a sudden became desperate to sell them again. We rule out this possibility, restricting our model to just one period.

\footnotetext{
${ }^{10}$ Given the significant dispersion of CDO losses, these differences are not statistically significant at the 5 percent level. We perform this analysis only for the High-Grade CDOs because there are few Mezzanine CDOs in our sample issued by dealers that are not vertically integrated.

${ }^{11}$ Mezzanine CDOs are classified as those that had assets with a weighted average rating factor (WARF) of BBB; High-Grade CDOs had a WARF of A or A-.
} 


\subsection{Securities}

Let $A=\{a(t): t=1, \ldots, N\}$ denote the set of existing securities, where $t$ denotes a particular security. The quantity of security $t$ is given by $a(t)$. The intrinsic value of security $t$, defined as the fair liquidation value of the underlying collateral, is $T(t), L \leq T(t) \leq U$. Importantly, this intrinsic value of the security does not depend on who holds the security. There may be several types of securities holders, which we index by $i$. An individual's portfolio is denoted $\mathbf{A}(i)=\{a(i, t): 1 \leq t \leq N\}$ and $a(t)=\sum_{i} a(i, t)$. The total intrinsic value of agent $i$ 's portfolio, $T T[\mathbf{A}(i)]$, is therefore

$$
T T[\mathbf{A}(i)]=\sum_{t} a(i, t) \cdot T(t)
$$

\subsection{Agents}

Agents are risk neutral and have preferences over the money they have on hand $(M)$ and the intrinsic value of the securities they hold. Their utility functions have the form

$$
U_{i}[M, \mathbf{A}(i)]=M+x(i) \cdot T T[\mathbf{A}(i)]
$$

where $x(i), 0<x(i) \leq 1, i=\{1,2, \ldots, I\}$ is an agent-specific discount factor. This discount factor reflects the fact that some agents are willing to sell their securities at a discount to their intrinsic value.

\subsubsection{The sellers}

Denote agents that own securities as sellers. Utility maximization implies that the minimum price that a current holder would require to relinquish a security with true payoff $T$ is $V_{s}(i)[T]=$ $x(i) T$, which we refer to as the value to the seller. Note that $V_{s}(i)[\cdot]$ maps a true payoff into a price, $V_{s}(i): \mathbf{T} \rightarrow \mathbf{P}$.

Definition 1. $T^{\max }(i)[p]$ is the maximal value of $T(t)$ that seller $i$ will offer when given the opportunity to sell securities for price $p$.

Because $V_{s}(i)[\cdot]$ is monotonic, $T^{\max }(i)[p]=V s(i)^{-1}[p]=p / x(i)$. Let $\mathbf{S}(i)[p]=\{a(i, t)$ : $\left.L<T(t) \leq T^{\max }[p]\right\} \subseteq \mathbf{A}(i)$ denote the set of securities that seller $i$ will offer at price $p$. We can now define our basic supply relationship:

Definition 2. The 'fruit bowl,' $\mathbf{S}[p]$, is the total set of securities that will be offered by all sellers at price $p$. That is, $\mathbf{S}[p]=\bigcup_{i} \mathbf{S}(i)[p]$. 
Note that $\mathbf{S}[p]$ maps $\mathbf{P} \rightarrow \mathbf{T}$. The average intrinsic value of the securities offered at a given price is

$$
A T[\mathbf{S}[p]]=E[T(t): t \in \mathbf{S}[p]]=\frac{\sum_{t \in \mathbf{S}[p]} a(t) \cdot T(t)}{\sum_{t \in \mathbf{S}[p]} a(t)} .
$$

\subsubsection{The buyer $(\mathrm{s})$}

Like the sellers, the representative buyer only cares about the average, or total, true payoff of the portfolio he acquires. However, the buyer may also require that the price he pays for the securities represent a discount, $x_{b}$, to their true payoff. Thus, when offered a set of securities $\mathbf{Z}$, he will value a draw from it at some fraction, $x_{b}$, of the elements' expected true payoff. ${ }^{12}$ That is, the maximal per-unit price the buyer is willing to pay for the securities in $\mathbf{Z}$, denoted by $V_{b}$, is

$$
V_{b}[\mathbf{Z}]=x_{b} \cdot E[T(t): t \in \mathbf{Z}]=\frac{x_{b} \cdot \sum_{t \in \mathbf{Z}} a(t) \cdot T(t)}{\sum_{t \in \mathbf{Z}} a(t)}=x_{b} \cdot A T[\mathbf{Z}] .
$$

We assume there are enough buyers so that in principle the entire set of securities could trade hands.

\subsection{Information Set}

For now we assume that

Assumption 2. $\mathbf{A}(i)$ and $x(i)$ are known to everyone, and

Assumption 3. it is impossible for the current holder of a security to credibly reveal its intrinsic value to a potential buyer.

In Section 6.2 we relax assumption 2. Also, when we take the model to the data, we will give the potential buyers the benefit of the doubt (lessening the information asymmetry) by endowing them with information on the vintage, seniority, and CDO type, as well as information on the distribution of the CDO intrinsic values.

\subsection{Market Structure and Equilibrium Characterization}

To compute the equilibrium, we further assume that

Assumption 4. sellers cannot coordinate with each other and that prices are determined via a Dutch auction.

\footnotetext{
${ }^{12}$ We will stick with tradition and frame this in terms of expectations. However, in the current setup there will be no uncertainty about the securities traded, so it is just as natural to think of this as the mean or average value of the securities traded rather than the expected value of a draw from the portfolio.
} 
Proposition 1. There is at least one $p^{c *}$ such that

$$
V_{b}\left[\mathbf{S}\left[p^{c *}\right]\right]=p^{c *}
$$

and if $T(1)>0$, then there is at least one $p^{c *}>0$ such that $V_{b}\left[\mathbf{S}\left[p^{c *}\right]\right]=p^{c *}$.

Proof. Recall that the intrinsic values, $T(t)$, are ordered such that $T(t)<T(t+1)$ for $t=$ $1, \ldots, N$. Let $p(t)^{s}=x_{s} \cdot T(t)$. This is the minimum price required for the sellers to willingly offer security $t$ into the fruit bowl. Obviously, at $p(t)^{s}$ the sellers will also offer all securities valued less than $\mathrm{T}(\mathrm{t})$. Consider the fruit bowl at $p(1)^{s}=x_{s} \cdot T(1)$. Only the lowest valued securities will be offered. As such, $\left.V_{b} \mathbf{S}\left[p(1)^{s}\right]\right]=x_{b} \cdot T(1)$. Since $x_{s}<x_{b}$, we know that $V_{b}\left[\mathbf{S}\left[p(1)^{s}\right]\right]=x_{b} \cdot T(1) \geq p(1)^{s}$ and, if $T(1)>0$, this is a strict inequality.

Now consider the prices $p \in\left[p(1)^{s}, p(2)^{s}\right)$ : As we increase prices to approach $p(2)^{s}$, no new securities are added, so $V_{b}[]$ does not change. At $p(2)^{s}$, the next most valuable securities are thrown into $\mathbf{S}[p]$, and both the average value of the bowl, $A T[\mathbf{S}[p]]$, and the value of the bowl to the buyer, $V_{b}[\mathbf{S}[p]]$, jump up. This repeats for higher $p$ and we have that $V_{b}[\mathbf{S}[p]]$ is a monotonically increasing step function in $p$. As such, it is upper semi-continuous (USC).

We also note that the maximal value that $V_{b}[]$ could ever reach would be $x_{b} \cdot T(N)$, which is the value to the buyers of the highest value securities alone. Pulling the pieces together, we have that $V_{b}[]$ is a USC function that maps $\left[x_{s} \cdot T(1), x_{b} \cdot T(N)\right]$ back onto itself. As such, we can apply Kakutani's fixed point theorem to establish that there is at least one $p^{c *} \in\left[x_{s} \cdot T(1), x_{b} \cdot T(N)\right]$ such that $V_{b}\left[\mathbf{S}\left[p^{c *}\right]\right]=p^{c *}$, which completes the proof.

In general there will be many such fixed points and we will index (label) them by $t$, corresponding to the highest value security thrown into the fruit bowl. That is $\mathbf{S}\left[p(t)^{c *}\right]=$ $\bigcup_{j \leq t} a(j)$.

Proposition 2. Every pair $\left(p(t)^{c *}, \mathbf{S}\left[p(t)^{c *}\right]\right)$ is a candidate equilibrium for the system in that the buyers and sellers would willingly trade $\mathbf{S}\left[p(t)^{c *}\right]$ at price $p(t)^{c *}$.

Proof. This comes directly from the definitions of $\mathbf{S}[]$ and $V_{b}[]$.

We note that for every candidate equilibrium $\left(p(t)^{c *}, \mathbf{S}\left[p(t)^{c *}\right]\right)$, if $p(t)^{c *}>0$, there is a continuum of prices in the neighborhood of $p(t)^{c *}$ at which the buyer and seller would willingly exchange $\left.\mathbf{S}\left[p(t)^{c *}\right]\right)$. This reflects the fact that $x_{s}$ is some discrete distance below $x_{b}$, so if there are gains from trading a specific set of securities, there is still some indeterminacy in how those gains are split between the buyer and seller.

In the analysis that follows, we want to be able to focus on the candidate equilibrium where the greatest number of securities trade and, for that trade, the highest price at which it will occur. To this end, we define the Dutch Auction Equilibrium (DAE). 
Definition 3. The DAE is the pair $\left(p^{*}, \mathbf{S}\left[p^{*}\right]\right)$, such that $p^{*}$ is maximal among all candidate equilibria.

We call this the Dutch Auction Equilibrium because it can be located as follows: Have an auctioneer call out $p^{H}=T(N) \cdot x_{b}$. This is the most the buyers would be willing to pay for a fruit bowl that only contained the highest value securities. At this price, the sellers would throw all their securities into the bowl and, if there is any dispersion in the value of the securities, the average value of the bowl will be less than $T(N)$, in which case the buyers will not be willing to pay $p^{H}$ for it. Since no trade takes place at $p^{H}$, the auctioneer then calls out continuously lower prices until he reaches a price consistent with a candidate equilibrium. The first such price is our DAE price $p^{*}$ and we denote by $T^{\max *}$ the maximal value of $T(t)$ offered by any seller at $p^{*}$. We note that at this price, the buyers are indifferent between trading or not and all the gains from trade go to the sellers. Buyers know they are "overpaying" for some low-value securities and "underpaying" for some high-value securities in the bowl they purchase, but on average they pay exactly what the bowl is worth to them 13

From Propositions 1 and 2, we know there will always be at least one DAE. However, this equilibrium may be associated with a "trivial trade," which we define as follows:

Definition 4. Trivial trades are those that involve only the lowest-value securities for a price equal to $L$ (which may be zero).

When we use the model to analyze how the CDOs in our data would trade under AI, we generally dismiss these niggling trades and instead focus on what we consider meaningful trades.

As an aside, we note that throughout the paper we are assuming that agents are risk neutral. If instead buyers were risk averse, they would value an uncertain draw from this bowl at something less than the expected value of its contents. This would have the same effect as lowering $x_{b}$, bringing the buyer's and seller's discount factors closer together, and decreasing the gains from trade. Thus, investor risk aversion would make trade even less likely under asymmetric information.

\footnotetext{
${ }^{13}$ The Dutch auction results in the high-price equilibrium being picked. Other auction mechanisms that could result in the low-price equilibrium being picked would make the effects of AI even stronger, resulting in fewer trades. Also, although buyers do not know the intrinsic values of the individual securities, there is no winner's curse in our setup because all buyers value the bundle of securities offered into the fruit bowl equally, based on their perfect knowledge of the distribution of the intrinsic values and their knowledge of the sellers' discount factor.
} 


\subsubsection{Graphical illustration of the equilibrium}

We demonstrate the equilibrium conditions graphically using the examples illustrated in Figures 1 through 4 . The top part of each panel shows how the equilibrium price $\left(p^{*}\right)$ is determined. The bottom part shows the distribution of securities in the market, and those that are traded at the equilibrium price.

Turning to the top portion of each panel, on the horizontal axis we plot the intrinsic value of the securities, $T$. On the vertical axis we plot the average price of a set of securities or the value of some set of securities to the holders. It will be handy to have a $45^{\circ}$ line $(p=T)$ which maps any security with intrinsic value $T$ into a price equal to $T$. When the buyer's discount $x_{b}=1$, the equilibria are the $\left(p^{*}, \mathbf{S}\left[p^{*}\right]\right)$ pairs such that $A T\left[\mathbf{S}\left[p^{*}\right]\right]=p^{*}$. On the graph, the equilibria occur when the $A T[\mathbf{S}[p]]$ line touches the $45^{\circ}$ line. Without regard to the distribution of securities we can also plot $V_{s}[T]$, which gives the minimum price that the seller would require to relinquish a security with payoff $T$. If all sellers have the same discount factor, call it $x_{s}$, then $V_{s}[T]=x_{s} T$ is just a ray from the origin with slope $x_{s}$, which is less than one. At the equilibrium price $p^{*}$, the corresponding $T^{\text {max* }}$ is given by $V_{s}^{-1}\left[p^{*}\right]$, and all securities with payoffs $T<T^{\text {max* }^{*}}$ will be offered into the fruit bowl and traded at that price.

\subsubsection{Examples with a uniform distribution}

To plot $A T[\mathbf{S}[p]]$ we need to know the distribution of the intrinsic values of the securities. To keep this first example simple, we will assume a uniform distribution on $T$ with lower and upper bounds $L$ and $U$. That is $\forall a(t) \in \mathbf{A}, a(t)=a$. In this case

$$
A T[\mathbf{S}[p]]=E\left[T: L<T(t)<T^{\max }\right]=\frac{\sum_{t \in \mathbf{S}[p]} a(t) \cdot T(t)}{\sum_{t \in \mathbf{S}[p]} a(t)}=\frac{\left(L+T^{\max }[p]\right)}{2}=\frac{\left(L+p / x_{s}\right)}{2} .
$$

By setting $A T\left[\mathbf{S}\left[p^{*}\right]\right]=p^{*}$ and solving for the resulting equilibrium price, we obtain $p^{*}=\frac{L x_{s}}{2 x_{s}-1}$.

Example 1. Figure 1 illustrates the case when the intrinsic values of the securities are uniformly distributed between $L=60$ and $U=130$. In the left panel, the sellers' discount factor is $x_{s}=0.8$. The equilibrium is such that some of the securities - those valued at $T^{\max ^{*}}=p^{*} / x_{s}=100$ or less - trade at a price $p^{*}=80$, which is equal to the average intrinsic value of all securities in the fruit bowl. In the right panel, the sellers are less desperate (their discount factor is $\left.x_{s}=0.95\right)$, so the equilibrium price is lower, and fewer securities are traded. 


\subsubsection{Examples with a more general distribution}

Example 2. Figure 2 illustrates an example where the distribution of securities has a small mass between $T=0$ and $T=7$, the seller's discount is not too small $\left(x_{s}=0.85\right)$ and yet there are no (non-trivial) trades in equilibrium. This example shows how a few lemons can disrupt trade.

Example 3. Figure 3 illustrates multiple equilibria. The Dutch auction results in trades at the equilibrium with the highest price $\left(p^{* *}\right)$. However, one could easily impose alternative rules on the bidding process.

Proposition 3. If all sellers have the same discount factor, $x_{s}$, and all buyers have the same discount factor, $x_{b}$, then the set of securities traded in equilibrium is determined by the ratio $x_{s} / x_{b}$.

Proof. By combining equations 2 and 3 and the fact that in equilibrium, $T^{\text {max* }}=p^{*} / x_{s}$, we have

$$
\frac{\sum_{t \in \mathbf{S}[p *]} a(t) \cdot T(t)}{\sum_{t \in \mathbf{S}[p *]} a(t) T^{\max ^{*}}}=\frac{x_{s}}{x_{b}} .
$$

The left-hand side of equation 4 measures the "junkiness" of the fruit bowl at the equilibrium price $p^{*}$ - the numerator is the total value of the securities in the fruit bowl, and the denominator is maximum possible value of the securities in the fruit bowl if they were all valued at $T^{\text {max* }^{*}}$. Equation 4 therefore implies that the junkier the securities offered into the fruit bowl, the larger the discount that sellers would have to accept (lower $x_{s}$ ) for trade to occur. Thus, as illustrated in Figure 4 , the ratio $x_{s} / x_{b}$ uniquely determines which securities trade in equilibrium, but the equilibrium price $p^{*}$ will depend on the level of either $x_{b}$ or $x_{s}$.

Aside from being a curiosity of the model, Proposition 3 provides us with a very handy shortcut when taking the data to the model. In particular, in judging whether or not the market could support trade, we do not need to make any assumptions about the agents' discount rates. Instead, the analysis can all be done in terms of the (ratio) difference of the agents' discount factors, which in turn can be viewed as a measure of the potential gains from trade.

\section{Data}

As demonstrated by Cordell, Huang, and Williams (2012), accurately valuing an ABS CDO requires a complex infrastructure capable of valuing the hundreds of bonds that comprise the 
underlying collateral. To that end, CHW use the Intex engine which covers the universe of publicly traded private-label RMBS and ABS CDO deals in the United States. The Intex engine not only warehouses data on the underlying collateral backing each CDO and on the underlying subprime bonds, it also programs into its cash-flow engine the structural features of each deal, such as loss allocations among the tranches, triggers, prepayment penalty allocations, and interest rate hedges. In principal, this allows buyers and sellers a common set of tools to generate their own valuations. In practice, as discussed in Section 3 , before the crisis investors used ratings or the popular and much less computationally intensive copula models to value the CDOs.

We use data on the intrinsic values of 4,865 individual CDO securities (from 672 CDO deals), computed as of March 2011 by CHW. Appendix A provides more details on how these intrinsic values are computed. It is important to note that, as of March 2011, roughly two-thirds of the original collateral balance in the CDOs had already been paid to investors, liquidated, or written off as losses. So most of the losses in the CDOs in our sample are actual, or realized, losses. The original CHW sample comprises $727 \mathrm{CDO}$ deals, but we exclude 55 deals from the 2000-2005 vintages that were liquidated as of March 2011 because they were likely liquidated before the financial crisis erupted in 2007. For each CDO deal, the securities are tranched based on their seniority. At the tranche level, there are 4,865 individual CDO securities in our sample: 734 Senior AAA, 1,009 Junior AAA, 1,387 AA and A, 828 BBB, $252 \mathrm{BB} / \mathrm{B}$, and $655 \mathrm{NR}$ (not rated, equity, or "first-loss" tranche). Mezzanine CDOs make up about two-thirds of the CDOs in our sample; the rest are High-Grade CDOs.

Roughly three-quarters of the 4,865 CDO bonds in the CHW data were originated between the second half of 2005 and the end of 2007. These CDOs experienced higher losses than those issued in earlier years because they are primarily backed by subprime securities and other ABS CDOs. As described above, underwriting standards for subprime mortgages deteriorated significantly over this period, as shown by the dramatic upward shift in the cumulative default rate curves for subprime loans starting in 2005 (Figure 5). CHW and Goodman, Li, Lucas, Zimmerman, and Fabozzi (2008) find that CDO losses increase by year of origination. Also, during the first half of 2005 ISDA published a template for executing credit default swaps of ABS on a Pay-As-You-Go basis, which made it easier to invest CDO collateral synthetically and brought about an explosion in synthetic CDO issuance starting in the second half of the year (see Figure 6). We therefore take CDO vintage into account when we examine how these securities trade under AI. To this end, we label CDOs that were issued on or before June 30, 2005 as the "early" vintage, and those issued after this date as the "late" vintage.

Table 4 summarizes the distributions of intrinsic values for the various CDO categories in our sample. Only the most senior tranches of the early vintage CDOs have average intrinsic 
values greater than 50. Most of the CDOs in the other tranches experienced heavy losses or became worthless $(T=0)$, resulting in low means and medians for their intrinsic values. Furthermore, the high standard deviations of the intrinsic values indicate that they are highly dispersed between 0 and 100 .

\section{Trading CDOs under asymmetric information}

We now examine how these 4,865 CDOs would trade when potential buyers cannot penetrate a CDO's portfolio to determine its intrinsic value; only the sellers can. Even so, to give the buyers the benefit of the doubt, we assume that they are equipped with some valuable information. That is, when considering the purchase of a CDO tranche they know its seniority, its vintage, and whether it is a High-Grade or Mezzanine CDO. But, more importantly, we assume that each buyer knows the true distribution of intrinsic values for the type of CDO he is considering to buy. One can think of each CDO as having a label (much like the label on a bottle of wine) with three stamps on it: a High-Grade or Mezzanine stamp, a Seniority stamp (e.g. Sr-AAA), and a vintage stamp (early or late). For example, a CDO's label may read "High-Grade, Jr-AAA, early vintage." Another CDO's label may read "Mezzanine, BBB, late vintage." We will consider trading in markets for CDOs that have the same label.

In Section 6.1, we examine trading under the assumption that all sellers have the same discount factor, $x_{s}$, which is known to the buyers. We relax this assumption in Section 6.2 by instead assuming that buyers do not know $x_{s}$, and place a uniform prior on it.

\subsection{Buyers know sellers' discount factor, $x_{s}$}

For now assume that buyers know the sellers' discount factor $\left(x_{s}\right)$. Sellers are assumed to know the intrinsic value of a CDO, but cannot credibly reveal this to the buyer ${ }^{14}$ Referring back to the model in Section 4 , buyers value a draw from the fruit bowl at the same price that elicited the fruit bowl to be filled. Assuming that prices are called following a Dutch auction, we compute the resulting trading equilibria for the various CDO markets. For any given label, we are interested in finding the equilibria for which 'meaningful trade' occurs, which we define in either of two ways:

\footnotetext{
${ }^{14}$ Just the possibility that the sellers are better informed than buyers is sufficient to shutter the market even if sellers are not actually better informed. If buyers fear (or place some probability on the possibility) that sellers know the intrinsic value of their individual securities, then the buyers will value a draw from the fruit bowl at some weighted average of (1) the average intrinsic value of all the securities for a given label-assuming sellers are ignorant of individual securities' values, and (2) the lower average value of what informed sellers would offer to the fruit bowl for a given price. Thus, if the weight attached to possibility (2) that sellers are informed is high enough, the market will collapse, even if few or no sellers are in fact well informed.
} 
Definition 5. Meaningful trade occurs when at least half of the market value for a given label is traded. As a robustness check, we will also use a looser definition of meaningful trade'Marginally meaningful trade,' when at least a quarter of the market value for a given label is traded.

For simplicity, we set the buyer's discount factor $\left(x_{b}\right)$ to 1 . This normalization is not important for our results because, as shown earlier, it is the ratio between the sellers' and buyer's discounts $\left(x_{s} / x_{b}\right)$ that uniquely determines which securities trade in equilibrium. The "junkier" the securities within the label, the more desperate sellers would have to be (relative to the buyers) in order for trade to occur. To determine the price at which they trade, we would still need knowledge of, or an assumption about, one of the discount factors.

Instead of arbitrarily fixing $x_{s}$ (known to buyers) and examining the resulting equilibria, we ask the following question: given the distribution of intrinsic values in our data, how desperate would the sellers have to be in order for there to be meaningful trade under AI? In other words, we solve for $x_{s}^{\max }$ defined as follows:

Definition 6. $x_{s}^{\max }$ is the maximum value of the sellers' discount factor for which meaningful trades occur. Likewise, the minimum haircut that sellers would be willing to take on the intrinsic value of their securities for there to be meaningful trade is $1-x_{s}^{\max }$.

We find $x_{s}^{\max }$ by running simulations of what trades as we incrementally lower $x_{s}$ from its starting value of 1 until meaningful trade occurs. The results are shown in Table 5 . For each of the CDO categories, the first column shows the maximum sellers' discount $\left(x_{s}^{\max }\right)$ that results in meaningful trade (see definition 5). Consider trading under AI in the High-Grade, seniorAAA, early vintage CDOs (first row), which were regarded as relatively safe before July 2007. For these securities, our model implies that over half of the market value would trade if the sellers' discount factor is 0.68 or less (a hair-cut of at least 32 percent). Figure $7 \mathrm{a}$ illustrates the graphical interpretation of the equilibrium when $x_{s}=x_{s}^{\max }=0.68$. At the equilibrium price $p^{*}=61$ the maximum value of $T$ that sellers will offer into the fruit bowl is $T^{\max ^{*}}=90$. As indicated by the grey-shaded bars in the bottom part of the panel, those securities having intrinsic values greater than 90 will not trade. We note that in such a case, holders who did not sell would have good reason to complain if they were forced to mark-to-market their securities, which are all worth more than 90, to the trade price of 61 .

Of all the CDO categories in our sample, the Mezzanine, Senior-AAA, early vintage CDOs suffered the least losses, and had an average intrinsic value of 84.5. Under AI, at least half of the market value for these securities would trade if the sellers discount factor is no higher than 0.84; that is, if sellers are willing to take a haircut of at least 16 percent. The resulting equilibrium when $x_{s}=x_{s}^{\max }=0.84$ is shown in Figure $7 \mathrm{~b}$; all securities trade. 
There are many more absolute lemons in the market for late vintage CDOs- which puts more mass in the far left tail of the distribution of values and imparts more "damaging" dispersion to the distribution. This implies that sellers would have to be more desperate to sell these securities (lower $x_{s}$ ) in order for there to be meaningful trade. For example, meaningful trade only occurs for the High-Grade, Senior-AAA, late vintage CDOs when the sellers' discount factor is 0.46 or less (a haircut of at least 54 percent). The resulting equilibrium with $x_{s}=x_{s}^{\max }=0.46$ is shown Figure 8 a. Only securities with $T \leq 59$ are offered into the fruit bowl and traded, at a price $p^{*}=27$. For the Mezzanine, Senior-AAA, late vintage CDOs, there are so many lemons that meaningful trade only occurs when the sellers' discount is 0.32 or smaller (a haircut of at least 68 percent). As shown in the Figure $8 \mathrm{~b}$, the resulting equilibrium with $x_{s}=x_{s}^{\max }=0.32$ is such that everything trades. This is a knife-edge equilibrium in the sense that raising the sellers discount by a shade would result in no trade at all. For all the other CDO categories shown in Table 5 (except for the early-vintage High-Grade and Mezzanine Sr-AAA CDOs), meaningful trade would only take place under AI if sellers would be willing to accept steep haircuts of at least 45 percent.

As a robustness check, the rightmost columns of the table show the equilibria when we use the alternative 'marginally meaningful trade' definition. For some of the CDO tranches, the maximum sellers' discount $\left(x_{s}^{\max }\right)$ that results in marginally meaningful trades are a bit higher, but overall the results are similar to those obtained using the first definition of meaningful trade.

\subsection{Buyers do not know sellers' discount factor, $x_{s}$}

Now we relax the assumption that buyers' know the sellers' discount factor by assuming that they place a uniform prior on $x_{s}$ that ranges between 0.3 and 0.7 . This prior range is purposely wide and embodies haircuts ranging from 30 to 70 percent, which seem plausible. We also assume that the true $x_{s}$ (unknown to the buyer) is that which results in meaningful trade (see definition 5), that is, $x_{s}^{\text {true }}=x_{s}^{\max }$ 15 The equilibria are defined by the pairs $\left(p^{*}\right.$ and $\left.\mathbf{S}\left[p^{*}\right]\right)$ such that $E\left(A T\left[\mathbf{S}\left[p^{*}\right]\right]\right)=p^{*}$, where the expectation for $E\left(A T\left[\mathbf{S}\left[p^{*}\right]\right]\right)$ is taken over the uniform prior for $x_{s}$; analogous to averaging the $A T\left[\mathbf{S}\left[p^{*}\right]\right]$ lines for each value that $x_{s}$ can take between 0.3 and 0.7 . The likelihood of trade is determined by buyers' belief about how desperate the sellers are (their prior on $x_{s}$ ) relative to the true (but unbeknownst to the buyer) value of $x_{s}$.

If the buyers think the sellers are truly desperate (most of the mass of their prior on $x_{s}$ is below $x_{s}^{\text {true }}$ ), then they expect the fruit bowl to contain higher-valued securities. This is the case for both High-Grade and mezzanine, early vintage, Sr-AAA CDOs. Figure 9a illustrates

\footnotetext{
${ }^{15}$ Using the alternative 'marginally meaningful trade' definition does not alter the results.
} 
the equilibrium for High-Grade, Sr.AAA, early vintage CDOs. The equilibrium price $p^{*}$ and corresponding $T^{\max *}$ is defined by the highest intersection of the blue $E\left(A T\left[\mathbf{S}\left[p^{*}\right]\right]\right)$ line and the $45^{\circ}$ line. Compared to the case when $x_{s}$ is known, trade is more likely to occur because buyers think that sellers are more desperate than they truly are: most of the mass of the prior on $x_{s}$, which ranges between 0.3 and 0.7 , is below the true (yet unknown) $x_{s}$ of 0.68 . For the same reason, trading in the Mezzanine Sr.AAA early-vintage CDOs is also more likely to occur when $x_{s}$ is unknown.

However, given the prior on $x_{s}$, for all the other CDO tranches uncertainty about $x_{s}$ shuts down trade entirely $\left(T^{\max }=0\right)$. That is because buyers think that the sellers are not that desperate (most of the mass of their prior on $x_{s}$ is above $x_{s}^{\text {true }}$ ), so they expect that the fruit bowl has relatively more lemons. For example, as illustrated in Figure 9b, our model predicts there is no trading of CDOs in the early-vintage Mezzanine Jr.AAA category because a sufficient mass of the prior is above $x_{s}^{\text {true }}=0.55$. That is, trade is less likely when buyers (erroneously) think that sellers are not so desperate, because they expect less of the 'good stuff' to be thrown into the fruit bowl.

All told, given the distribution of intrinsic values of CDOs, our model implies that unless sellers were desperate to rid themselves of these securities, only the highest rated, early vintage CDOs would trade under AI. If trading did take place for the late vintage and less senior securities, our model would predict that these securities would have traded at prices well below their intrinsic values. Both of these findings are consistent with the sharp decline in secondary market activity for ABS CDOs that took place in the second half of 2007, and the earlier-cited IOSCO survey response that "the hold-to-maturity value of many structured finance products exceeds the value that could be attained in the current secondary market."

\section{Why the CDO market existed in the first place}

Given that AI was already present in the market even before the crisis, why did the market for CDOs exist in the first place? Perhaps the original CDO buyers did not know what they were getting into, and were thus defrauded by the issuers and the ratings agencies. This view is supported by numerous lawsuits and enforcement actions against CDO issuers and ratings agencies. From 2010 to 2014, crisis-era mortgage-related legal settlements for some of the largest U.S. banks totalled more than $\$ 120$ billion (Financial Stability Oversight Council, 2015).

Alternatively, we can examine the possibility that the original buyers knew everything we have assumed, including how AI would, conditional on a housing shock, shutter the market. In this case, we can ask what is the maximum probability of a housing shock that would still 
make the CDOs an attractive investment, which we refer to as the break-even probability of a crisis, $\tilde{\pi}$. If $\tilde{\pi}$ is fairly high, we can imagine that buyers could have assigned a somewhat lower probability to a crisis occurring, in which case the existence of the market is consistent with the AI we have assumed.

To compute $\tilde{\pi}$, we assume that, before considering the purchase of a CDO (at par), investors are fully aware that their payoff will depend on whether or not a housing crisis occurs at some point in the future ${ }^{16}$ Specifically, we assume that:

Assumption 5. Without a housing crisis, CDOs would continue to pay their annual coupons and principal as promised. That is, the CDO would pay a fixed coupon (a spread over the 3-month Libor rate) for 7 years.

And that,

Assumption 6. If a crisis occurs (with probability $\pi$ ), it does so in the third year, so investors would still receive the first 2 annual coupons. In the third year, CDO investors would: (a) incur heavy losses on their CDO from payment shortfalls, resulting in much lower intrinsic values (i.e., those summarized in Table 4); (b) be desperate to sell their CDO (i.e. their discount factor $x_{s}$ would equal $x_{s}^{\max }$ from the first column of Table 5); and, (c) have to do so in an environment where potential future buyers believe that sellers are better informed (AI holds). Although ex-ante buyers do not know the post-crisis intrinsic value of any particular CDO they acquire, they do know the distribution of post-crisis intrinsic values for the CDOs in the same category, which are summarized in Table 4 .

With these assumptions, the break-even probability of a crisis, $\tilde{\pi}$, is that which equates the par value of a CDO with the expected value of its cash flow (where the expectation is taken over the probability of the crisis): ${ }^{17}$

$$
100=(1-\pi)\left(\left(\sum_{k=1}^{7} \rho^{k} \text { Coupon }\right)+\rho^{7} 100\right)+\pi\left(\left(\sum_{k=1}^{2} \rho^{k} \text { Coupon }\right)+\rho^{3} E(\text { T } \mid \text { Crisis })\right),
$$

where the discount factor $\rho=1 /(1+$ Libor $/ 100), E[$ T $\mid$ crisis $]=\left(w_{1} \cdot p^{*}\right)+\left(w_{2} \cdot A T[\right.$ not traded $\left.] \cdot x_{s}^{\max }\right), w_{1}=\operatorname{Prob}\left(T \leq T^{\max }\right)$, and $w_{2}=\operatorname{Prob}\left(T>T^{\max }\right)$. The first term on the

\footnotetext{
${ }^{16}$ For convenience, we will use the term "crisis" to refer to any event which causes CDOs to suffer large losses.

${ }^{17}$ Based on conversations with market participants, before 2007 most CDOs were either sold at par or very close to par (in the high 90s). The breakeven probabilities would increase somewhat if we instead assume that CDOs were purchased at a small discount, because such a discount would increase its yield, making the CDO an even more attractive investment relative to the risk free asset. This would further strengthen the case for the existence of the CDO market under AI.
} 
right-hand side of equation 5 is simply the discounted value of the 7 annual coupon payments and the principal payment at maturity, which the ex-ante investor would expect to receive if no crisis occurs, multiplied by the probability of no crisis $(1-\pi)$ (see Assumption 5). The second term is the discounted value of what the ex-ante investor would expect to receive if a crisis occurs, times the probability of a crisis $(\pi)$, based on Assumption 6. To compute $E(T \mid$ Crisis $)$, the ex-ante buyer considers the likelihood of having to place the CDO in the fruit bowl when trying to sell it in the future, versus holding it until maturity. They will place their CDO in the fruit bowl and sell it for the equilibrium price $p^{*}$ if its post-crisis intrinsic value (unknown ex-ante) is less than or equal to $T^{\max }$. Based on the known distribution of post-crisis CDO intrinsic values, this occurs with probability $w_{1}$ (shown in column 3 ). If the CDO's post-crisis intrinsic value is greater than $T^{\max }$, which occurs with probability $w_{2}$, the CDO is held to maturity and is worth $A T[$ not traded $] \cdot x_{s}^{\max }$.

The break-even probabilities are shown in column 6 of Table6. For example, the break-even probability for the early vintage High-Grade CDO is estimated to be 0.08. That is, before the crisis, an investor would have preferred to purchase a CDO in this category rather than invest the same amount of money in a risk-free asset that pays the 3-month Libor rate as long as she believes that the probability of such crisis is less than 8 percent. The break-even probabilities for the less senior tranches and the Mezzanine tranches are higher because these securities pay higher coupons. This suggests that investors may have required extra compensation to hold these riskier securities given the likelihood of a crisis. In column 7, the break-even probabilities are computed under the assumption that investors remain patient even during a crisis $\left(x_{s}=1\right)$. In this case, ex-ante investors value their CDOs in the crisis state according to their expected intrinsic values, which is simply the average true value of all CDOs in that category, or $A T[\mathbf{A}]$ (same as means in Table 4). Therefore, to compute the break-even probability of a crisis, we can simply replace $E(T \mid$ Crisis $)$ with $A T[\mathbf{A}]$ in equation 5. Recall that for most tranches, the equilibrium when sellers become desperate $\left(x_{s}=x_{s}^{\max }\right)$ is such that all securities are thrown into the fruit bowl $\left(w_{1}=1\right)$ and traded at $p^{*}$, which is equal to the average true value of all securities $A T[\mathbf{A}]$. So for these tranches the break-even probabilities when sellers are patient shown in column 7 are unchanged because $E[T \mid$ crisis $]=p^{*}=A T[\mathbf{A}]$. For the other tranches the probabilities are also very similar because $w_{1}$ is close enough to 1 , which makes $A T[\mathbf{A}]$ close to $p^{*}$.

These break-even probabilities suggest that most of the CDOs were attractive investments even if investors believed that there was a 1 in 20 chance of a major housing crisis occurring (with the exception of the late-vintage High-Grade Sr-AAA and Junior-AAA tranches). Although the interpretation of these probabilities is subjective, they appear to be higher than those generally attached to a severe housing crisis back in 2005, when the CDO market was 
in full gear. For example, in a survey of investment bank reports from 2005-2008, Gerardi, Lehnert, Sherlund, and Willen (2008) find that the consensus view among analysts was for a slowdown in house price appreciation, and that the risk of a national decline in house prices was remote. They further document how "the belief that such a widespread and steep decline in house prices could not occur persisted even long after prices began to fall" (p.140). In sum, investment bank reports from the 2005-2006 period suggest that investors placed almost no probability on a housing meltdown. This would imply that CDO coupons were attractive enough to entice even those investors that may have been aware of the AI problem and the potential for a severe housing crisis, which in turn would help explain the existence of this market.

In computing these break-even probabilities, we have assumed that both ex-ante (pre-crisis) and ex-post (conditional on a crisis) buyers are risk neutral. However, if ex-ante buyers are risk averse, they will value the expected CDO's cash flow (where the expectation is taken over the probability of the crisis) at something less than the equivalent cash flow from investing in the alternative risk free asset. This has the effect of lowering the break-even probability of a crisis. The assumption that ex-post buyers are risk neutral means they are willing to value a draw from the fruit bowl at the average value of what will have been thrown into the bowl. If instead ex-post buyers are risk averse, they will value an uncertain draw from this bowl at something less than the expected value of its contents. This would have the same effect as lowering $x_{b}$ and bringing the effective discount rates closer together. In other words, ex-post sellers would have to be even more desperate (lower $x_{s}$ ) for there to be trade, lowering $p^{*}$ and $T^{\max }$, which in turn lowers $w 1$ and the break-even probability of a crisis. Thus with risk averse investors there would be less appetite for CDOs to begin with, and the effects of AI would be stronger if a crisis occurs. All told, these two factors would lower the break-even probability of a crisis, making the existence of this market harder to justify if investors knew about the extent of the AI problem.

\section{Conclusion}

The 2007-2008 financial crisis led to a freezing of CDO markets and a disconnect between market prices (for the few trades that did occur) and fundamentals. Home mortgages were securitized through a long chain of financial intermediaries, which culminated in the creation of CDOs. Securitization rules gave CDO sellers an inherent information advantage since securities were allowed to be placed after the issue date. Also, many of the largest CDO dealers were fully integrated (doing originations, issuance of RMBS, issuance of CDOs, and, finally, servicing the mortgages), which gave them an informational advantage over potential 
buyers. We show how this asymmetric information between buyers and sellers could have amplified the stresses already present in CDO markets, by making these markets illiquid and dislodging prices from intrinsic values.

Using a novel dataset on the distribution of intrinsic values of structured finance ABS CDOs, we examine which securities would trade under AI. The likelihood of trade depends not only on the distribution of intrinsic values of the CDOs but also on the ratio between the sellers' and buyers' discount factors. For the 4,865 CDO bonds in our sample, we find that the informational problems were so severe that most of the CDOs would not trade unless the sellers were willing to sell their securities at a very steep discount to their intrinsic values.

We take this as evidence that asymmetric information about the intrinsic values of the CDOs was sufficient to cause CDOs to stop trading and their prices to be well below what most holders valued them at. This is not to imply that AI was the only factor leading to the market's breakdown. Indeed there were likely many factors. The question we ask is if AI was strong enough to cause this. The experiment is to give the potential buyers less information than current holders and determine the conditions under which there would be significant trades. Because we give the buyers perfect information about the distribution of the intrinsic values within relative narrow groups of securities, the experiment is rigged to find that AI alone is not sufficient to shutter these markets. However, given the increased dispersion of the CDO intrinsic values, we find that AI would have been sufficient to close the markets. For a couple of labels we find trades even when sellers are not massively desperate for cash; their discount factors are greater than 0.5. But in these two cases only the junkiest of the securities trade. We therefore conclude that the information asymmetries were sufficient to shut down the CDO market.

More recently there have been a few large CDO transactions, such as the Federal Reserve's sale of its ABS CDOs held by Maiden Lane III in 2012. Amid improving economic fundamentals, other large investors have paid the fixed cost to value these securities using commercially available tools, and a few large bilateral trades have occurred. But ABS CDOs are no longer being issued and, if one buys our results, they may never.

\section{Appendix A - Securitization From Mortgage Loans to CDOs and Methodology for Computing CDO Intrinsic Values}

The residential mortgage market experienced tremendous growth in securitization over the last decade. We focus on the securitization of private label securities, in particular structured finance ABS CDOs. These CDOs are backed, in part, by mortgages that do not conform to the 
criteria for purchase by Fannie Mae and Freddie Mac, which establish limits on debt-to-income ratio, documentation requirements, and maximum loan amount. We note, however, that our results readily apply to the $\mathrm{ABCP}$ market as well, which experienced runs in the second half of 2007. Similar to ABS CDOs, ABCP issuers did not disclose information about specific assets in their portfolios to investors because these information were deemed as proprietary trading strategies (Covitz, Liang, and Suarez, 2013).

The securitization chain begins with the pooling of prime, Alt-A, subprime, and juniorlien mortgages into residential mortgage-backed securities (RMBS). These RMBS securities are tranched based on seniority, with senior note holders having priority over the principal and interest payments collected from the underlying loans. This senior-subordinate structure is often referred to as the "waterfall." The most senior notes are rated AAA because they are the last to incur losses stemming from loan defaults. Generally, the AAA-, AA-, and A-rated RMBS are purchased by so-called "High-Grade" ABS CDOs, whereas the BBB-, and BB-rated RMBS are purchased by "Mezzanine" ABS CDOs. These CDOs are also issued with senior/subordinate structures. Finally, both High-Grade and Mezzanine ABS CDOs are purchased by other CDOs, which are often referred to as CDO-squareds because they are primarily backed by CDOs ${ }^{18}$

The CDO intrinsic values are calculated as the liquidation value of the underlying ABS (mostly RMBS) collateral- the value that a CDO bondholder would receive if the CDO manager sold all the underlying ABS bonds and allocated the proceeds according to the CDO bondholders' positions in the waterfall structure. Valuing the 213 CDOs that were already liquidated as of March 2011 is fairly straightforward, since this involves simply summing up the actual principal payments made to the CDO bondholders as reported in the trustee's final liquidation report provided to Intex (or from other sources if it was not). Table 7 in CHW shows that the 213 liquidated SF CDO deals experienced losses of $\$ 162$ billion, a loss rate of 78 percent.

For the 514 non-liquidated, or active, CDOs (as of March 2011), the idea is to compute the expected fair liquidation values of the still-active underlying ABS (mostly RMBS) collateral, and then feed these as recovery amounts into the CDO waterfall. The fair liquidation values of the underlying RMBS are, in turn, computed using realized and expected write-downs on the underlying mortgage loans and securities, computed from models described below. First, CHW determine that, of the $\$ 432.6$ billion original balance of CDO collateral, $\$ 75.9$ billion in principal had already been paid back to the CDO bondholders, while $\$ 134.4$ billion had already been written down as losses as of March 2011. This leaves $\$ 222.3$ billion in ABS

\footnotetext{
${ }^{18} 628$ of the 727 CDOs in the Cordell, Huang, and Williams (2012) data had at least some CDOs as collateral, so they define a CDO-squared as having at least 50 percent of the total deal collateral as CDOs.
} 
collateral backing the 514 still active CDOs.

The next step is to determine the fair liquidation value of this remaining $\$ 222.3$ billion of CDO collateral by estimating expected losses, and then feeding these recovery values into the CDO waterfall to determine how much each ABS CDO bond recovers, and ultimately loses. Table 8 in CHW describes the methodologies used for valuing the 23,147 unique securities underlying these active CDOs. Roughly two-thirds are RMBS, which are backed by subprime, Alt-A and prime mortgages. These RMBS were valued using the proprietary prepayment, default, and loss models of Andrew Davidson \& Company, a leading market modeling vendor, which is seamlessly integrated with the Intex cash flow engine for valuation and loss estimation. 19 Each ABS collateral asset (or loan) contributes its fair value liquidation proceeds to the ABS deal, with the aggregate recovery amounts allocated in the Intex software to the various tranches of the ABS CDO deals according to the CDO waterfall ${ }^{20}$ All told, CHW estimated $\$ 123$ billion in expected write-downs stemming from these ABS bonds underlying the still active CDOs (on top of the $\$ 134.4$ billion that had already been written down).

As of March 2011 the actual write downs of $\$ 162$ billion for the 213 liquidated SF CDOs combined with $\$ 134$ billion actual and $\$ 123$ billion expected write-downs for the 514 still active SF CDOs sum up to a grand write-down total of $\$ 420$ billion, 65 percent of the $\$ 641$ billion of ABS of CDO issuance (Table 10 in CHW). While different valuation methods can be used to estimate ABS CDO losses, it is noteworthy that as of March 2011, 71 percent of the writedowns had already been realized. Of the remaining 29 percent of estimated write-downs $(\$ 123$ billion), most came from still-active BBB- and A-rated subprime and alt-A RMBS securities that were trading at values at or new zero. Based on this, loss estimates will not likely vary much by the valuation method chosen.

\section{References}

Adrian, T., AND H. S. SHIn (2010): "Liquidity and leverage," Journal of Financial Intermediation, 19(3), $418-437$.

Akerlof, G. A. (1970): "The Market for 'Lemons': Quality Uncertainty and the Market Mechanism," The Quarterly Journal of Economics, 84(3), 488-500.

Caballero, R. J., And A. Simsek (2009): "Fire Sales in a Model of Complexity," NBER Working Papers 15479, National Bureau of Economic Research, Inc.

\footnotetext{
${ }^{19}$ See http://www.ad-co.com/. The advantage of using a leading market vendor is that their fair values are good representations of what investors will pay in the market for these RMBS securities.

${ }^{20}$ For CDOs that have other CDOs as collateral, CHW first compute the fair liquidation values of the underlying CDOs, and then feed these values together with those of all other assets in the CDO's portfolio into the CDO's waterfall to determine the tranche payoffs.
} 
Cordell, L., Y. Huang, And M. Williams (2012): "Collateral damage: Sizing and assessing the subprime CDO crisis," Working Papers 11-30, Federal Reserve Bank of Philadelphia.

Covitz, D., N. Liang, And G. A. Suarez (2013): "The Evolution of a Financial Crisis: Collapse of the Asset-Backed Commercial Paper Market," The Journal of Finance, 68(3), 815-848.

Creditflux Ltd. (2009): "Creditflux tally of credit write-downs as of January 26, 2009," http://www. creditflux.com/Assets/Documents/Creditfluxwritedowns.xls

Dang, T. V., G. Gorton, And B. Holmström (2015): "Ignorance, Debt and Financial Crises," Working paper.

DeMarzo, P., And D. Duffie (1999): “A Liquidity-Based Model of Security Design,” Econometrica, 67(1), $65-100$.

Demarzo, P. M. (2005): "The Pooling and Tranching of Securities: A Model of Informed Intermediation," Review of Financial Studies, 18(1), 1-35.

Financial Stability Oversight Council (2015): "FSOC Annual Report," p.58, https://www.treasury.gov/ initiatives/fsoc/studies-reports/Documents/2015FSOCAnnualReport.pdf.

Gerardi, K., A. Lehnert, S. M. Sherlund, And P. Willen (2008): "Making Sense of the Subprime Crisis," Brookings Papers on Economic Activity, 39(2 (Fall)), 69-159.

Goodman, L. S., S. Li, D. J. Lucas, T. A. Zimmerman, And F. J. Fabozzi (2008): Subprime Mortgage Credit Derivatives. John Wiley \& Sons, Inc.

Gorton, G. (2009): "Information, Liquidity, and the (Ongoing) Panic of 2007," American Economic Review, $99(2), 567-72$.

Gorton, G., AND A. Metrick (2012): "Securitized banking and the run on repo," Journal of Financial Economics, 104(3), 425-451.

Gorton, G., And G. Pennacchi (1990): "Financial Intermediaries and Liquidity Creation," Journal of Finance, 45(1), 49-71.

IOSCO (2009): "Transparency of Structured Finance Products," Consultation report, International Organization of Securities Commissions.

Lucas, D. J., L. S. Goodman, And F. J. Fabozzi (2006): Collateralized Debt Obligations, Structures and Analysis. John Wiley \& Sons, Inc., second edn.

Moody's Investor Service (2007): “Moody's downgrades subprime first-lien RMBS,” Jul 10, 2007.

New York Times (2007): "BNP Paribas suspends funds because of subprime problems," August 9, 2007, http://www .nytimes . com/2007/08/09/business/worldbusiness/09iht-09bnp.7054054.html.

Standard \& Poor's (2007): “612 U.S. Subprime RMBS Classes Put on Negative Watch; Methodology Revisions Announced," Ratings Announcement: July 10, 2007.

U.S. Department of the Treasury (2009): "Public-Private Investment Program," March 23, 2009 White Paper. 


\section{Tables}

\begin{tabular}{lrrrrr} 
& $\begin{array}{r}\text { ABS } \\
\text { CDOs }\end{array}$ & $\begin{array}{r}\text { Corp. } \\
\text { Credit }\end{array}$ & RMBS & $\begin{array}{r}\text { Other or } \\
\text { Undefined }\end{array}$ & $\begin{array}{r}\text { Total } \\
\text { Write- } \\
\text { downs }\end{array}$ \\
\hline \hline Insurers/asset managers & 61,074 & 6,320 & 10,386 & 3,8347 & 116,126 \\
North American banks & 84,319 & 23,702 & 42,272 & 59,011 & 209,305 \\
European banks & 63,464 & 18,579 & 26,423 & 62,634 & 171,100 \\
Asia/emerging market banks & 9,358 & 4,724 & 5,728 & 3,743 & 23,553 \\
Totals & $\mathbf{2 1 8 , 2 1 6}$ & $\mathbf{5 3 , 3 2 4}$ & $\mathbf{8 4 , 8 1 0}$ & $\mathbf{1 6 3 , 7 3 5}$ & $\mathbf{5 2 0 , 0 8 4}$ \\
Share of total writedowns & $\mathbf{4 2 \%}$ & $\mathbf{1 0 \%}$ & $\mathbf{1 6 \%}$ & $\mathbf{3 2 \%}$ & $\mathbf{1 0 0 \%}$ \\
\hline
\end{tabular}

Table 1: Crisis-Related ABS CDO writedowns. Data are through January 26, 2009, and are expressed in millions of dollars. Source: Creditflux Ltd. (2009). Based on publicly disclosed company information compiled by Creditflux Ltd. According to Creditflux, ABS CDO writedowns were no longer reported separately after February 2008. By this time, most firms had substantially written down their holdings. 
Level of

\begin{tabular}{|c|c|c|c|c|}
\hline CDO Dealers & Originators & Servicers & RMBS Shelves & Integration \\
\hline Merrill & $\begin{array}{l}\text { First Franklin (2006), } \\
\text { Ownit (2005) }\end{array}$ & $\begin{array}{l}\text { Wilshire Credit, First } \\
\text { Franklin (2006) }\end{array}$ & $\begin{array}{l}\text { SURF, MLHEL, } \\
\text { MLMI, MLFF, MLFF } \\
\text { in } 2007\end{array}$ & Full \\
\hline Citigroup & $\begin{array}{l}\text { CitiFinancial (2000), } \\
\text { Argent (2007) }\end{array}$ & $\begin{array}{l}\text { CitiMortgage, AMC Mtge. } \\
\text { Services (2007) }\end{array}$ & $\begin{array}{l}\text { Citigroup Mtge. Trust, } \\
\text { Salomon Brother } \\
\text { Mtge., Citifinancial } \\
\text { Mtge., Citicorp Res. }\end{array}$ & Full \\
\hline UBS & -- & -- & MASTR & Partial \\
\hline Goldman Sachs & $\begin{array}{l}\text { Southern Pacific (1999), } \\
\text { Senderra Funding (2007) }\end{array}$ & Litton Servicing (2007) & GSABS, GSAMP & Partial \\
\hline Credit Suisse & DLJ Mtge. (2000) & SPS (2004) & $\begin{array}{l}\text { ABSHE, HEAT, } \\
\text { HEMT, CSFB Mtge }\end{array}$ & Full \\
\hline Deutsche Bank & $\begin{array}{l}\text { Chapel Funding (2006), } \\
\text { MortgageIT (2006) }\end{array}$ & Chapel Funding (2006) & ACE & Full \\
\hline Wachovia & -- & -- & $\begin{array}{l}\text { Wachovia Asset } \\
\text { Securitization }\end{array}$ & Partial \\
\hline RBS & -- & -- & SVHE & Partial \\
\hline Calyon & -- & -- & -- & None \\
\hline Bank of America & Countrywide (2008) & Countrywide (2008) & BAFC & Partial \\
\hline Barclays & Equifirst (2007) & HomeEq(2006) & $\begin{array}{l}\text { SABR, EquiFirst Loan } \\
\text { Sec. Trust }\end{array}$ & Full \\
\hline Lehman Brothers & $\begin{array}{l}\text { BNC (2003), Aurora } \\
\text { (2003), Finance America } \\
\text { (2004), SIB Mtge. (2004), } \\
\text { Preferred Mtge. (2004) }\end{array}$ & Aurora (2003) & $\begin{array}{l}\text { SAIL, ARC, SASCO, } \\
\text { SASC, BNC Mtge. } \\
\text { Loan Trust, Finance } \\
\text { America Mtge. Loan } \\
\text { Trust }\end{array}$ & Full \\
\hline Bear Stearns & Encore Credit (2007) & EMC & $\begin{array}{l}\text { BSABS, EMC Mtge. } \\
\text { Loan Trust, Encore } \\
\text { Credit }\end{array}$ & Full \\
\hline Morgan Stanley & $\begin{array}{l}\text { Saxon (2006), } \\
\text { CityMortgage(2006) }\end{array}$ & Saxon & $\begin{array}{l}\text { MSAB, MSHE, } \\
\text { MSDW, MS Mtge. } \\
\text { Loan Trust }\end{array}$ & Full \\
\hline WestLB & -- & -- & -- & None \\
\hline SG Corporate & -- & -- & $\begin{array}{l}\text { SG Mtge. Securities } \\
\text { Trust }\end{array}$ & Partial \\
\hline Dresdner & -- & -- & -- & None \\
\hline JP Morgan & $\begin{array}{l}\text { Chase Home Finance, } \\
\text { WAMu (2008) }\end{array}$ & $\begin{array}{l}\text { Chase Home Finance, } \\
\text { WaMu (2008) }\end{array}$ & $\begin{array}{l}\text { JPM Mtge. Acquisition } \\
\text { Trust, CFLAT, CFAB }\end{array}$ & Full \\
\hline
\end{tabular}

Table 2: CDO Dealer Vertical Integration of Subprime Securitization. The table shows the acquisition of subprime originators and servicers (along with dates where available), and lists names of RMBS issuance shelves run by each dealer. Sources: Intex for issuance volume, numerous industry sources for other data. 


\begin{tabular}{|c|c|c|c|c|}
\hline \multirow[b]{2}{*}{ Level of integration } & \multicolumn{2}{|c|}{ Junior-AAA } & \multicolumn{2}{|c|}{ Senior-AAA } \\
\hline & $\begin{array}{l}\text { Loss rate } \\
\text { (percent) }\end{array}$ & $\begin{array}{r}\text { No. of } \\
\text { CDOs }\end{array}$ & $\begin{array}{l}\text { Loss rate } \\
\text { (percent) }\end{array}$ & $\begin{array}{r}\text { No. of } \\
\text { CDOs }\end{array}$ \\
\hline$\overline{\overline{\text { Full integration }}}$ & 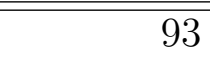 & 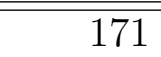 & 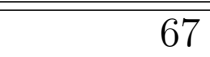 & 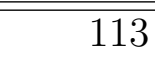 \\
\hline Partial integration & 88 & 111 & 65 & 91 \\
\hline No integration & 70 & 54 & 63 & 32 \\
\hline
\end{tabular}

Table 3: Losses on Late-Vintage High-Grade CDOs by Level of Dealers' Vertical Integration. Average losses are weighted by deal size. Sources: CHW for CDO losses, numerous industry sources for other data. 


\begin{tabular}{|c|c|c|c|c|c|c|c|}
\hline CDO category & $\begin{array}{c}\text { No. of } \\
\text { Secs. }\end{array}$ & $\begin{array}{c}\text { No. of } \\
\text { Secs. } \\
T>0\end{array}$ & $\begin{array}{l}\text { Mean, } \\
A T[\mathbf{A}]\end{array}$ & Median & Max & Min & $\begin{array}{l}\text { Std. } \\
\text { Dev. }\end{array}$ \\
\hline \multicolumn{8}{|l|}{ High-Grade } \\
\hline \multicolumn{8}{|l|}{ Early vintage } \\
\hline Sr-AAA & 56 & 55 & 66.3 & 67.8 & 100.0 & 0.0 & 25.0 \\
\hline Jr-AAA & 67 & 52 & 28.9 & 0.8 & 100.0 & 0.0 & 38.4 \\
\hline $\mathrm{AA} / \mathrm{A}$ & 79 & 29 & 4.5 & 0.0 & 100.0 & 0.0 & 15.2 \\
\hline $\mathrm{BBB}$ & 44 & 22 & 8.3 & 0.4 & 58.6 & 0.0 & 14.0 \\
\hline $\mathrm{BB} / \mathrm{B}$ & 9 & 0 & 0.0 & 0.0 & 0.0 & 0.0 & 0.0 \\
\hline $\mathrm{NR}$ & 41 & 1 & 2.4 & 0.0 & 98.6 & 0.0 & 15.4 \\
\hline \multicolumn{8}{|l|}{ High-Grade } \\
\hline \multicolumn{8}{|l|}{ Late vintage } \\
\hline Sr-AAA & 236 & 217 & 34.5 & 33.8 & 100.0 & 0.0 & 26.2 \\
\hline Jr-AAA & 349 & 182 & 8.6 & 0.0 & 100.0 & 0.0 & 20.6 \\
\hline $\mathrm{AA} / \mathrm{A}$ & 412 & 124 & 1.7 & 0.0 & 100.0 & 0.0 & 9.2 \\
\hline $\mathrm{BBB}$ & 178 & 49 & 1.8 & 0.0 & 100.0 & 0.0 & 10.7 \\
\hline $\mathrm{BB} / \mathrm{B}$ & 61 & 16 & 1.2 & 0.0 & 15.7 & 0.0 & 3.2 \\
\hline NR & 185 & 4 & 1.0 & 0.0 & 100.0 & 0.0 & 8.7 \\
\hline \multicolumn{8}{|l|}{ Mezzanine } \\
\hline \multicolumn{8}{|l|}{ Early vintage } \\
\hline Sr-AAA & 126 & 126 & 84.5 & 88.4 & 100.0 & 42.1 & 16.3 \\
\hline Jr-AAA & 184 & 147 & 55.2 & 68.2 & 100.0 & 0.0 & 42.8 \\
\hline $\mathrm{AA} / \mathrm{A}$ & 254 & 110 & 18.4 & 0.0 & 100.0 & 0.0 & 34.6 \\
\hline $\mathrm{BBB}$ & 208 & 103 & 13.8 & 0.0 & 100.0 & 0.0 & 25.8 \\
\hline $\mathrm{BB} / \mathrm{B}$ & 49 & 6 & 1.9 & 0.0 & 66.2 & 0.0 & 9.8 \\
\hline NR & 142 & 7 & 2.2 & 0.0 & 100.0 & 0.0 & 14.0 \\
\hline \multicolumn{8}{|l|}{ Mezzanine } \\
\hline \multicolumn{8}{|l|}{ Late vintage } \\
\hline Sr-AAA & 316 & 261 & 32.4 & 19.1 & 100.0 & 0.0 & 34.1 \\
\hline Jr-AAA & 409 & 152 & 7.7 & 0.0 & 100.0 & 0.0 & 21.4 \\
\hline $\mathrm{AA} / \mathrm{A}$ & 642 & 163 & 3.2 & 0.0 & 100.0 & 0.0 & 14.7 \\
\hline $\mathrm{BBB}$ & 398 & 211 & 4.1 & 0.2 & 100.0 & 0.0 & 12.8 \\
\hline $\mathrm{BB} / \mathrm{B}$ & 133 & 61 & 4.4 & 0.0 & 100.0 & 0.0 & 12.2 \\
\hline NR & 287 & 8 & 1.5 & 0.0 & 100.0 & 0.0 & 11.8 \\
\hline
\end{tabular}

Table 4: Summary statistics for distribution of CDO intrinsic values as of May 2011. 


\begin{tabular}{|c|c|c|c|c|c|c|c|c|}
\hline \multirow[b]{2}{*}{ CDO Category } & \multicolumn{4}{|c|}{ MV Cutoff $=0.50$} & \multicolumn{4}{|c|}{ MV Cutoff $=0.25$} \\
\hline & $x_{s}^{\max }$ & $T^{\max }$ & $\begin{array}{r}\text { Share MV } \\
\text { traded }\end{array}$ & $\frac{p^{*}}{A T[\mathbf{A}]}$ & $x_{s}^{\max }$ & $T^{\max }$ & $\begin{array}{r}\text { Share MV } \\
\text { traded }\end{array}$ & $\frac{p^{*}}{A T[\mathbf{A}]}$ \\
\hline \multicolumn{9}{|l|}{$\begin{array}{l}\text { High-Grade } \\
\text { Early vintage }\end{array}$} \\
\hline Sr-AAA & 0.68 & 90 & 81 & 92 & 0.70 & 71 & 43 & 75 \\
\hline Jr-AAA & 0.28 & 100 & 100 & 100 & 0.28 & 100 & 100 & 100 \\
\hline $\mathrm{AA} / \mathrm{A}$ & 0.04 & 100 & 100 & 100 & 0.09 & 22 & 45 & 45 \\
\hline $\mathrm{BBB}$ & 0.17 & 29 & 55 & 59 & 0.24 & 15 & 36 & 41 \\
\hline $\mathrm{BB} / \mathrm{B}$ & 0.00 & 0 & 0 & 0 & 0.00 & 0 & 0 & 0 \\
\hline NR & 0.02 & 99 & 100 & 100 & 0.02 & 99 & 100 & 100 \\
\hline \multicolumn{9}{|l|}{$\begin{array}{l}\text { High-Grade } \\
\text { Late vintage }\end{array}$} \\
\hline Sr-AAA & 0.46 & 59 & 68 & 78 & 0.46 & 59 & 68 & 78 \\
\hline Jr-AAA & 0.09 & 68 & 71 & 72 & 0.09 & 68 & 71 & 72 \\
\hline $\mathrm{AA} / \mathrm{A}$ & 0.02 & 40 & 50 & 47 & 0.02 & 40 & 50 & 47 \\
\hline $\mathrm{BBB}$ & 0.01 & 100 & 100 & 100 & 0.03 & 11 & 25 & 22 \\
\hline $\mathrm{BB} / \mathrm{B}$ & 0.08 & 11 & 68 & 67 & 0.08 & 11 & 68 & 67 \\
\hline NR & 0.01 & 100 & 100 & 100 & 0.01 & 100 & 100 & 100 \\
\hline \multicolumn{9}{|l|}{$\begin{array}{l}\text { Mezzanine } \\
\text { Early vintage }\end{array}$} \\
\hline Sr-AAA & 0.84 & 100 & 100 & 100 & 0.84 & 100 & 100 & 100 \\
\hline Jr-AAA & 0.55 & 100 & 100 & 100 & 0.55 & 100 & 100 & 100 \\
\hline $\mathrm{AA} / \mathrm{A}$ & 0.18 & 100 & 100 & 100 & 0.18 & 100 & 100 & 100 \\
\hline $\mathrm{BBB}$ & 0.13 & 100 & 100 & 100 & 0.17 & 28 & 30 & 34 \\
\hline $\mathrm{BB} / \mathrm{B}$ & 0.02 & 66 & 100 & 100 & 0.02 & 66 & 100 & 100 \\
\hline NR & 0.02 & 100 & 100 & 100 & 0.02 & 100 & 100 & 100 \\
\hline \multicolumn{9}{|l|}{$\begin{array}{l}\text { Mezzanine } \\
\text { Late vintage }\end{array}$} \\
\hline Sr-AAA & 0.32 & 100 & 100 & 100 & 0.32 & 100 & 100 & 100 \\
\hline Jr-AAA & 0.07 & 100 & 100 & 100 & 0.07 & 100 & 100 & 100 \\
\hline $\mathrm{AA} / \mathrm{A}$ & 0.03 & 100 & 100 & 100 & 0.03 & 100 & 100 & 100 \\
\hline $\mathrm{BBB}$ & 0.08 & 23 & 48 & 48 & 0.10 & 17 & 37 & 39 \\
\hline $\mathrm{BB} / \mathrm{B}$ & 0.08 & 30 & 54 & 54 & 0.10 & 11 & 26 & 27 \\
\hline NR & 0.01 & 100 & 100 & 100 & 0.01 & 100 & 100 & 100 \\
\hline
\end{tabular}

Table 5: Trading under asymmetric information. $x_{b}$ is normalized to 1 . The first half of the table uses the first definition of meaningful trade (see definition 5) to compute $x_{s}^{\max }$, the maximum value of $x_{s}$ for which at least half of the market value trades. The second half of the table uses the alternative definition ('marginally meaningful trade') to compute $x_{s}^{\max }$, the maximum value of $x_{s}$ for which at least a quarter of the market value trades. The corresponding $T^{\max }$ is the maximal value of $T$ that sellers will offer into the fruit bowl. $A T[\mathbf{A}]$ is the average value of the CDOs of a given category (same as means in Table 4). 


\begin{tabular}{|c|c|c|c|c|c|}
\hline CDO Cat & $p^{*}$ & $\begin{array}{l}\text { AT }[\text { not } \\
\text { traded }]\end{array}$ & $w_{1}$ & $w_{2}$ & Coupon \\
\hline
\end{tabular}

\section{High-Grade}

Early vintage

Sr-AAA

Jr-AAA

92.4

$98.4 \quad 0.88$

0.12

4.04

0.08

0.09

$\mathrm{AA} / \mathrm{A}$

100.0

$0.0 \quad 1.00$

0.00

4.54

0.09

0.09

$\mathrm{BBB}$

59.4

$0.0 \quad 1.00$

0.00

5.04

0.10

0.10

$50.9 \quad 0.93$

0.07

7.70

0.24

0.25

\section{High-Grade}

Late vintage

Sr-AAA

Jr-AAA

$\mathrm{AA} / \mathrm{A}$

78.0

72.3

$81.8 \quad 0.87$

0.13

3.96

0.04

0.04

47.3

$98.2 \quad 0.98$

0.02

4.16

0.04

0.04

BBB

100.0

$100.0 \quad 0.99$

0.01

5.10

0.10

0.10

$\begin{array}{lll}0.0 & 1.00 & 0.00\end{array}$

7.81

0.24

0.24

\section{Mezzanine}

\section{Early vintage}

Sr-AAA

100.0

100.0

0.0

1.00

0.00

4.10

0.18

0.18

Jr-AAA

100.0

$0.0 \quad 1.00$

0.00

4.63

0.14

0.14

$\mathrm{AA} / \mathrm{A}$

100.0

$0.0 \quad 1.00$

0.00

5.51

0.14

0.14

BBB

$\begin{array}{lll}0.0 & 1.00 & 0.00\end{array}$

8.10

0.28

0.28

\section{Mezzanine}

Late vintage

Sr-AAA

Jr-AAA

100.0

100.0

$\begin{array}{lll}0.0 & 1.00 & 0.00\end{array}$

$\begin{array}{lll}0.0 & 1.00 & 0.00\end{array}$

4.01

0.05

0.05

$\mathrm{AA} / \mathrm{A}$

100.0

$0.0 \quad 1.00$

4.36

0.06

0.06

$\mathrm{BBB}$

48.5

$\begin{array}{lll}67.4 & 0.97 & 0.03\end{array}$

5.31

0.11

0.11

8.44

0.27

0.27

Table 6: Break-even probability of crisis. Columns (6) and (7) show the break-even probability of a crisis that would make an ex-ante investor indifferent between purchasing a CDO (at par) that pays a fixed coupon (3-month Libor + spread) for 7 years or investing in a risk-free asset that pays the 3-month Libor rate. See Section 7 for details. 


\section{Figures}

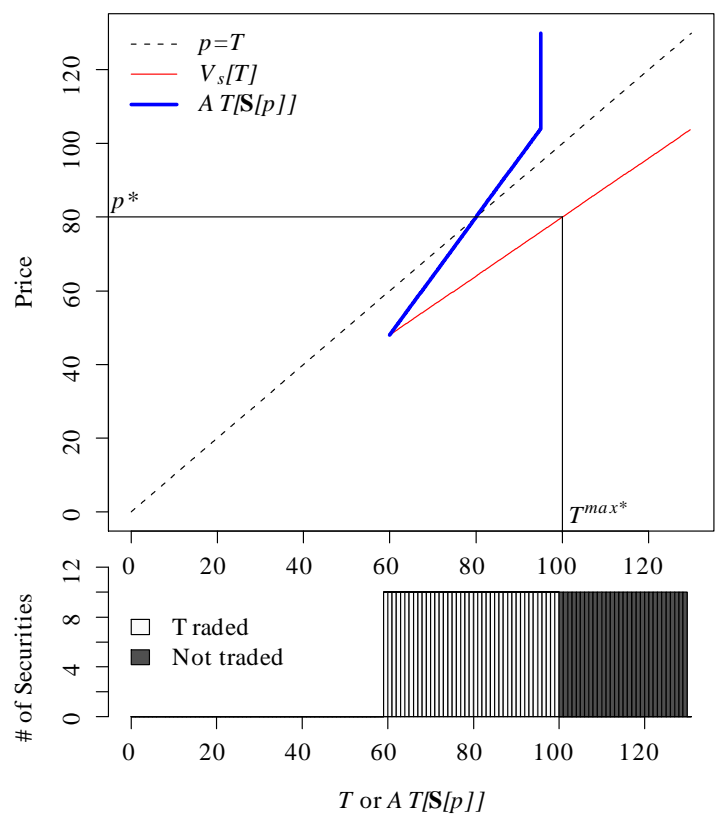

(a) $x_{s}=0.80$

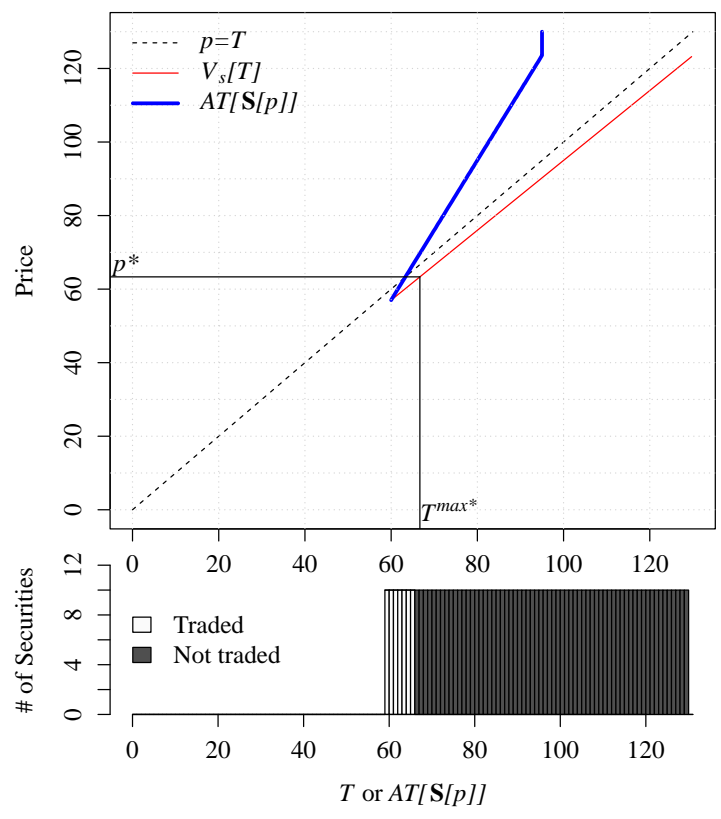

(b) $x_{s}=0.95$

Figure 1: Examples with a uniform distribution for intrinsic values. In panel (a), the equilibrium price is $p^{*}=80$, and securities worth less than $T^{\text {max }}{ }^{*}=100$ are traded. In panel (b), the equilibrium price is $p^{*}=63$, and securities worth less than $T^{\text {max }}=67$ are traded. 


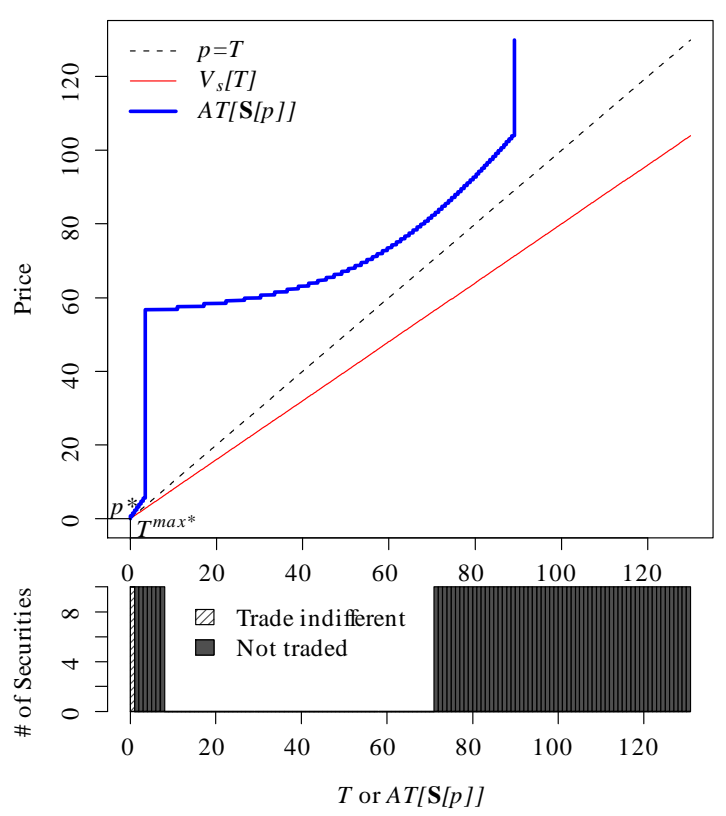

Figure 2: A few lemons ruin the market. The equilibrium price is 0 , and there are only trivial trades $\left(T^{\max }=0\right)$.

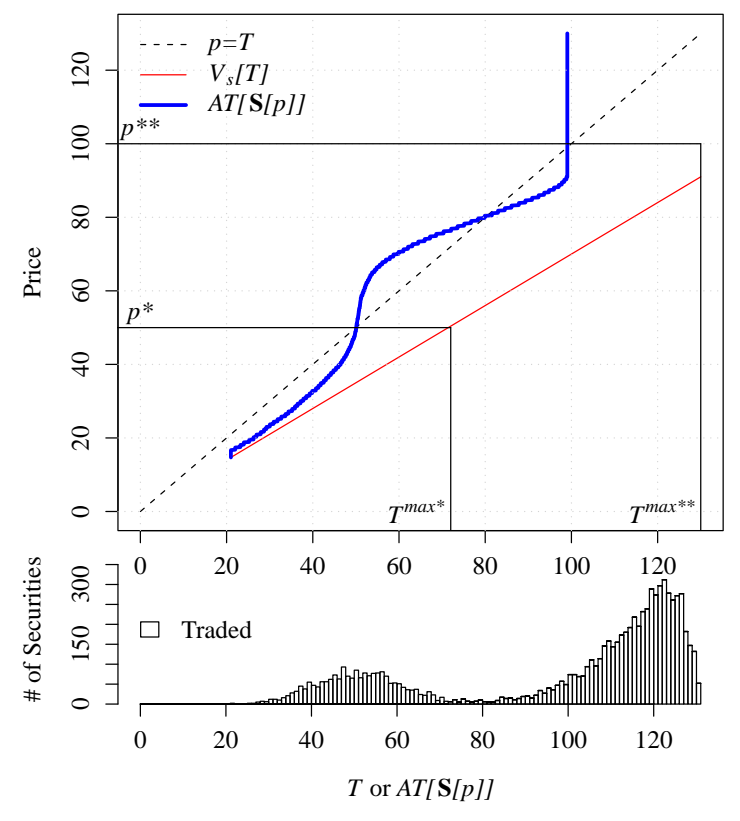

Figure 3: Multiple equilibria. The Dutch auction results in trades at the equilibrium with the highest price, $p^{* *}=100$, in which all securities trade. 


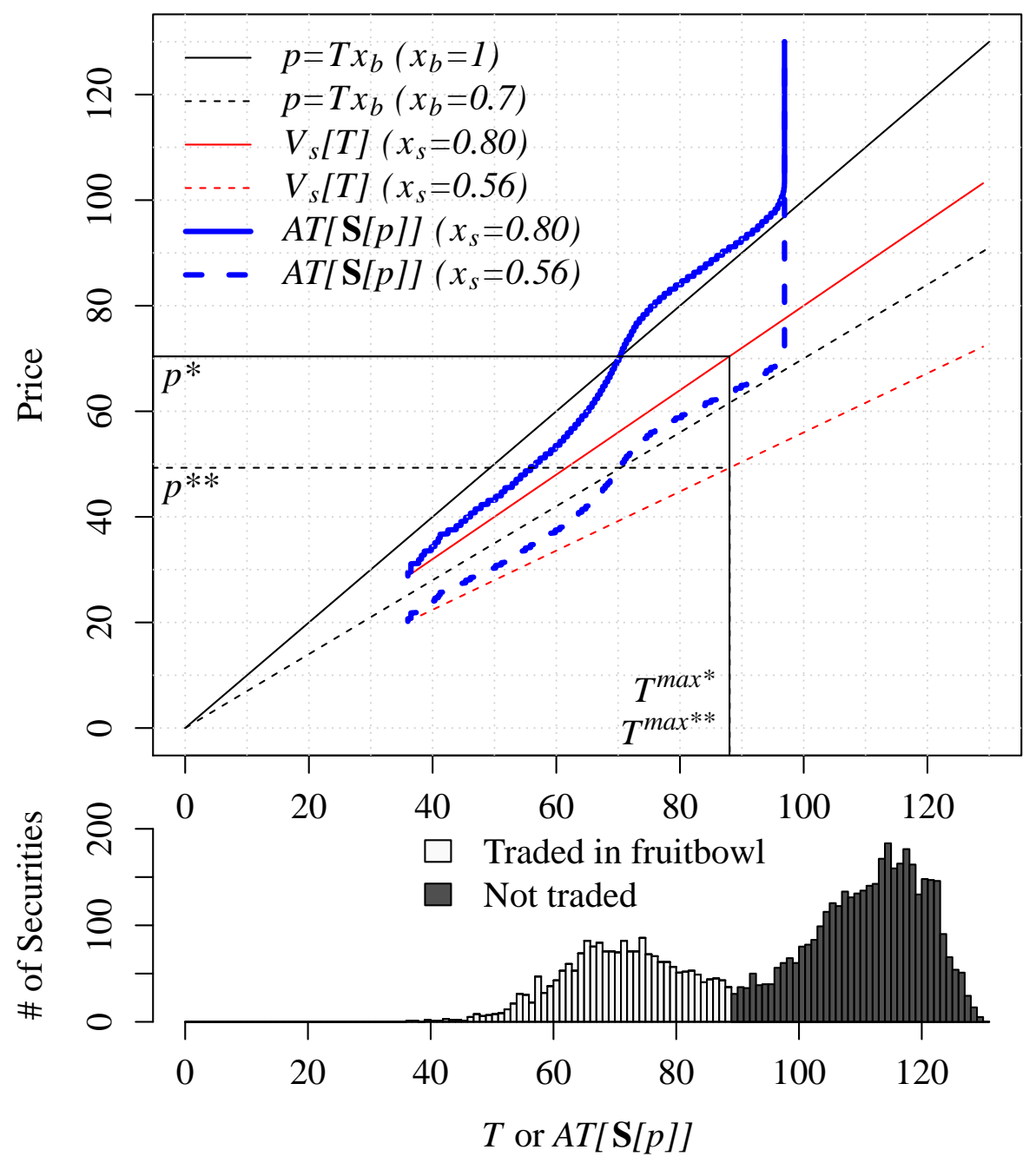

Figure 4: Ratio $x_{s} / x_{b}$ uniquely determines which securities trade in equilibrium. When $x_{s}=0.80$ and $x_{b}=1$, only securities with intrinsic values $T^{\text {max* }}=87$ or less trade at a price $p^{*}=70$, which is determined by the intersection of the solid $A T[\cdot]$ line and the $45^{\circ}$ line. When $x_{s}=0.56$ and $x_{b}=0.70$, the same set of securities trade $\left(T^{\text {max** }}=T^{\text {max* } *}\right)$ at a lower price $p^{*}=49$ (determined by the intersection of the dashed $A T[\cdot]$ line and the $45^{\circ}$ line) because the ratio $x_{s} / x_{b}$ is the same. 


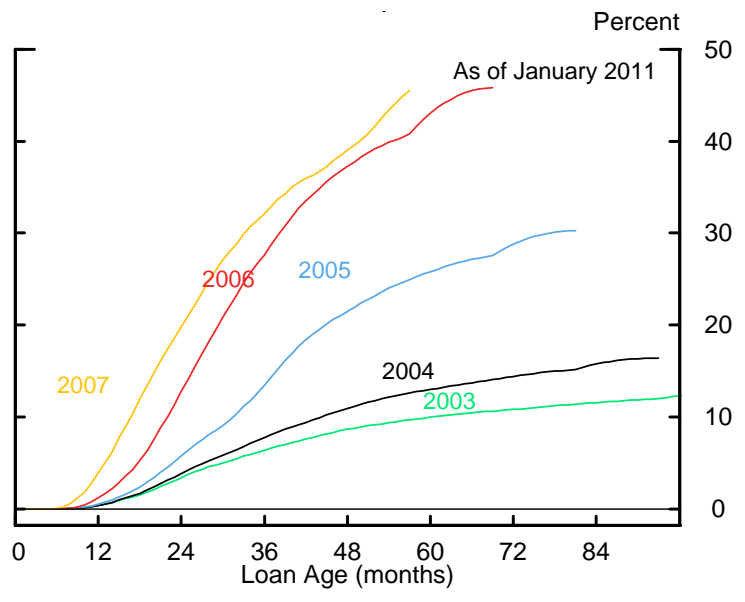

Figure 5: Cumulative defaults on subprime loans. Source: Federal Reserve Board calculations using CoreLogic data.

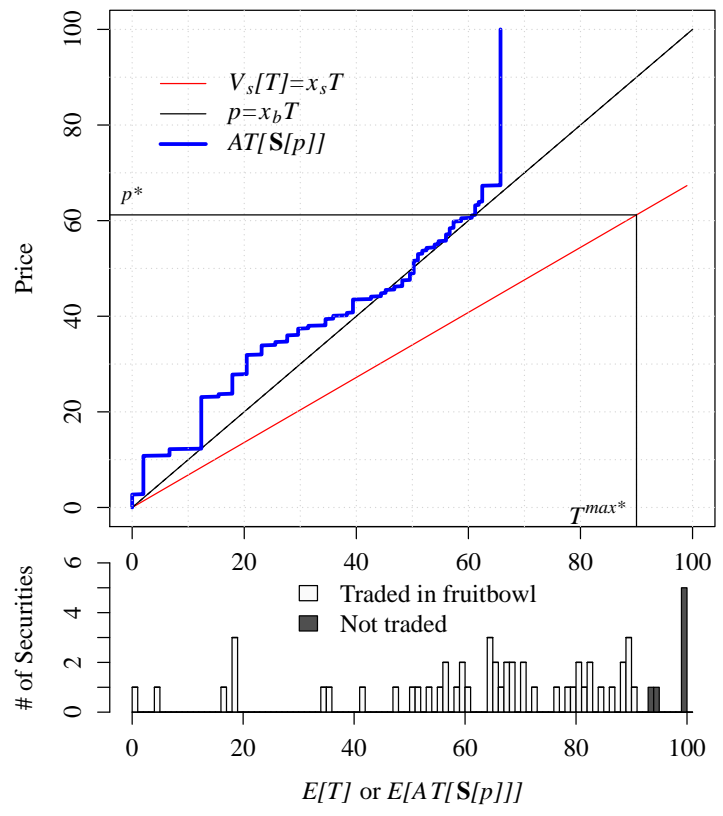

(a) High-Grade

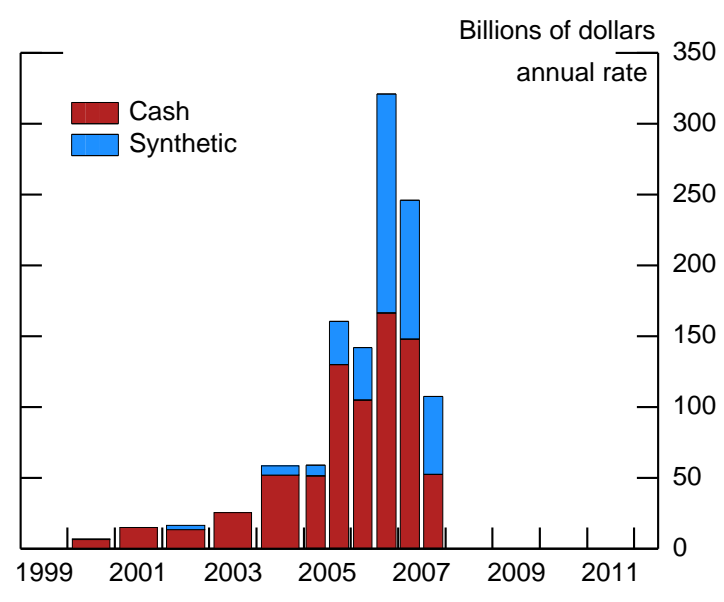

Figure 6: Issuance of publicly traded SF ABS CDOs. Source: Cordell, Huang, and Williams (2012).

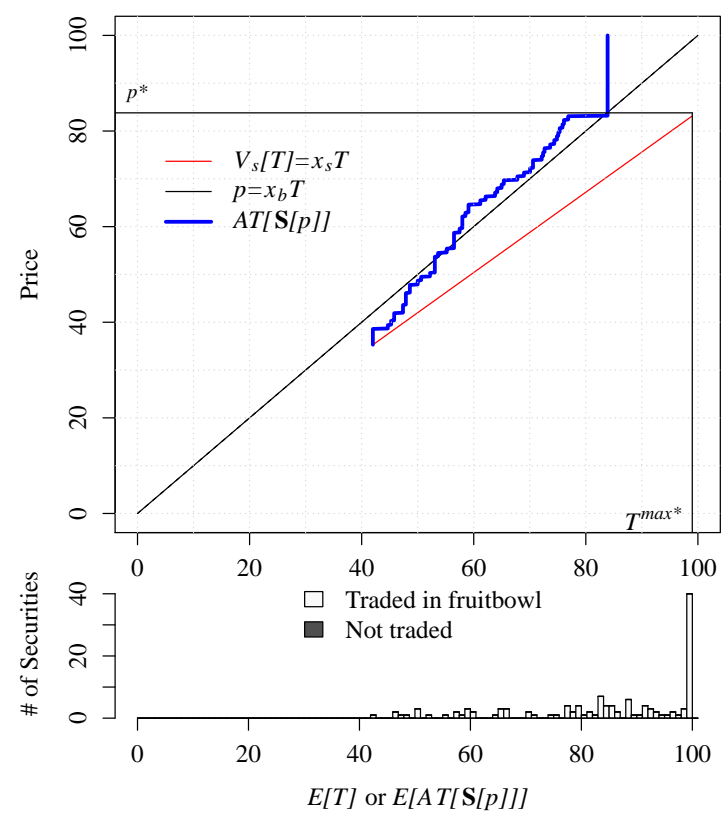

(b) Mezzanine

Figure 7: Trading of early vintage Sr-AAA rated CDOs. Left panel: Meaningful trade (see definition 5) occurs at a price $p^{*}=61$ when $x_{s}=0.68$. Securities worth $T^{\max }=90$ or less trade. Right panel: Meaningful trade occurs at a price equal to $p^{*}=84$ when $x_{s}=0.84$. All securities trade. 


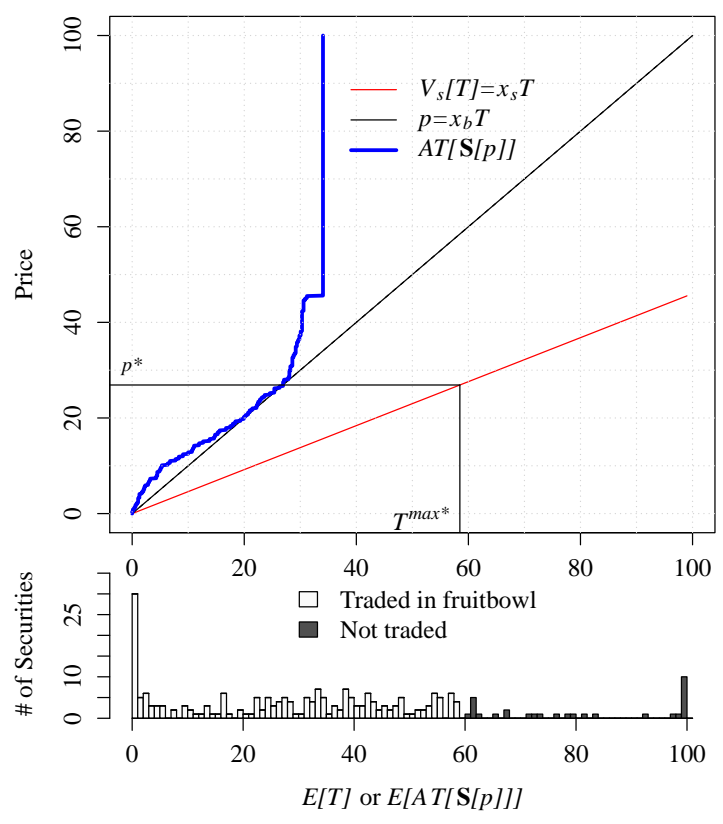

(a) High-Grade

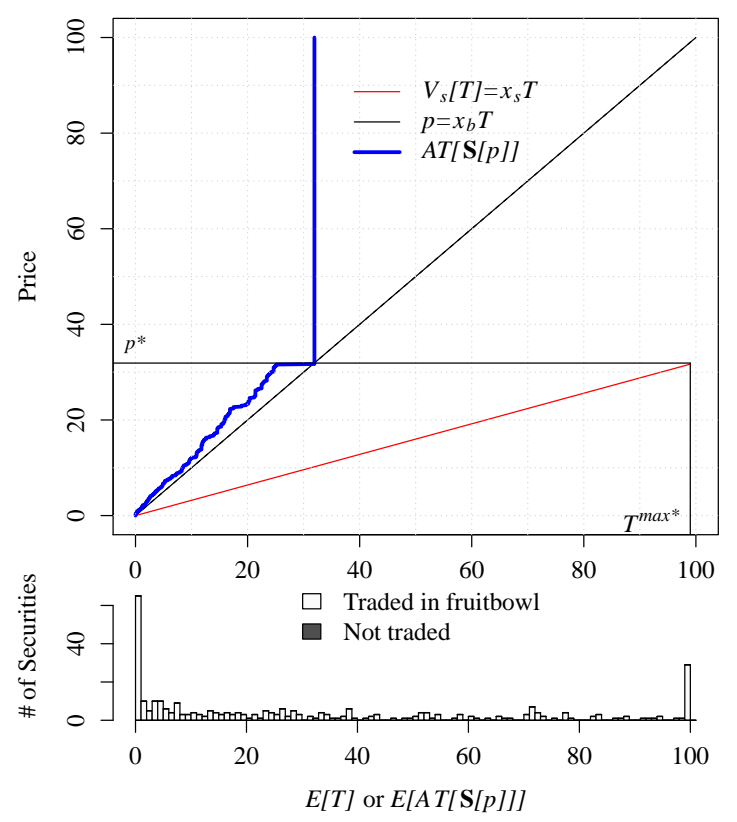

(b) Mezzanine

Figure 8: Trading of late vintage Sr-AAA rated CDOs. Left panel: Meaningful trade (see definition 5) occurs at a price $p^{*}=27$ when $x_{s}=0.46$. Securities worth $T^{\text {max }}=59$ or less trade. Right panel: Meaningful trade occurs at a price equal to $p^{*}=32$ when $x_{s}=0.32$. All securities trade. 


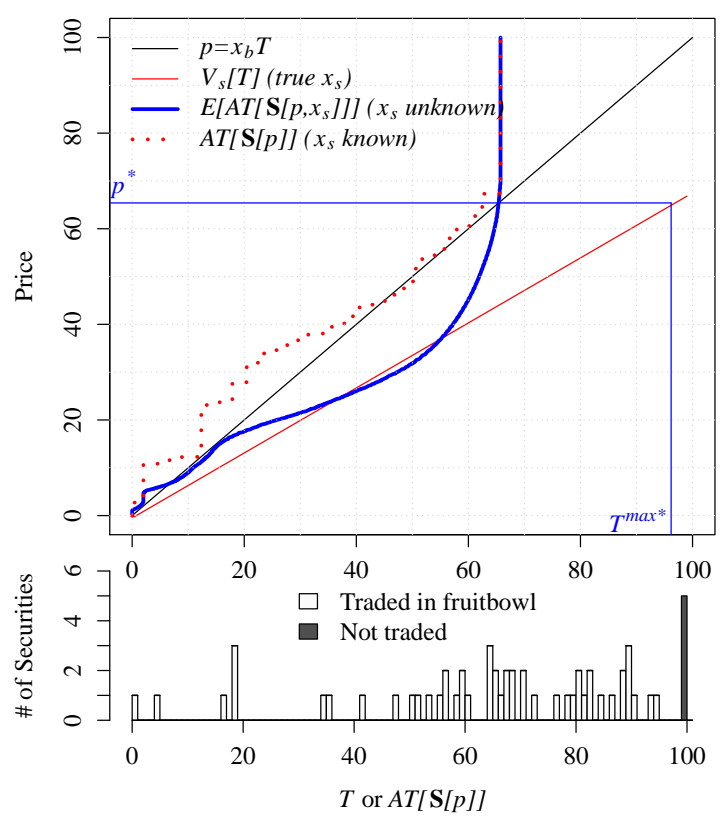

(a) High-grade, Sr.AAA

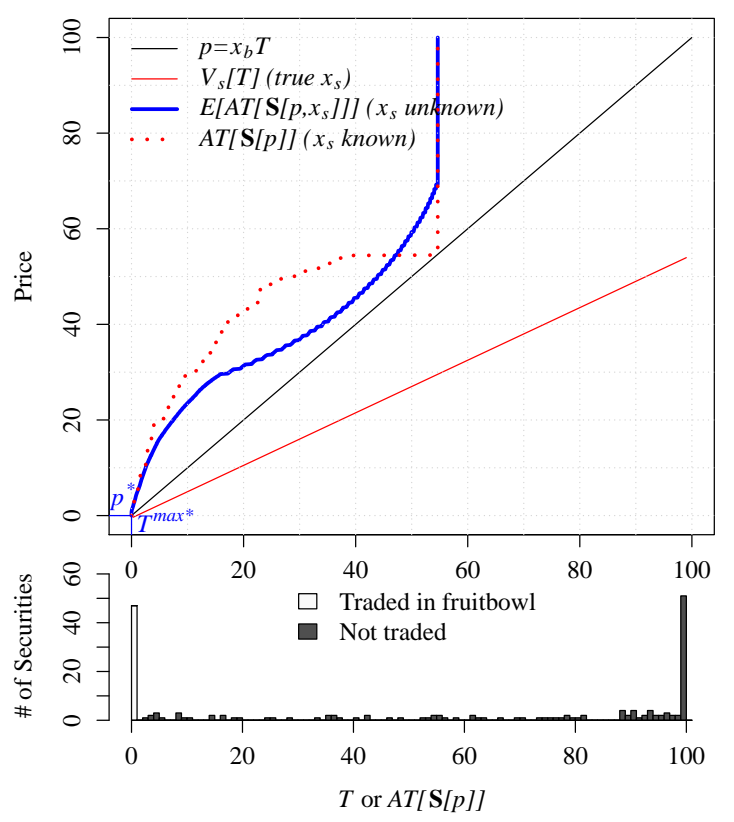

(b) Mezzanine, Jr.AAA

Figure 9: Trading of early vintage CDOs when $x_{s}$ is unknown. Buyers place a uniform prior on $x_{s}$ with bounds $(0.3,0.7)$. Left panel: Securities worth $T^{\max }=95$ or less trade at a price $p^{*}=65$ when $x_{s}^{\text {true }}=0.68$ is unknown to buyers. Right panel: Only trivial trades $\left(T^{\max }=0\right)$ occur at a price $p^{*}=0$ when $x_{s}^{\text {true }}=0.55$ is unknown to buyers. 